\title{
Asymptotic behaviour of Hilbert space contractions
}

\author{
A thesis submitted for the degree of \\ Doctor of Philosophy \\ by \\ ATtila Szalai
}

\begin{abstract}
Supervisor:
Prof. LÁSZLÓ KÉRCHY

Doctoral School in Mathematics and Computer Science University of Szeged, Bolyai Institute

Szeged, 2015
\end{abstract}




\section{Contents}

1 Introduction 3

1.1 Motivation and background ................. 4

1.2 Thesis outline . . . . . . . . . . . . . . . . . . 7

2 Stability results $\quad 9$

2.1 Contractions . . . . . . . . . . . . . . . . . 9

2.2 Polynomially bounded operators . . . . . . . . . . . . . . 13

3 Hyperinvariant subspaces of quasianalytic contractions $\quad 16$

3.1 Local quasianalytic spectral set . . . . . . . . . . . . . . . 16

3.2 Quasianalytic contractions . . . . . . . . . . . . . . 20

3.3 Asymptotically cyclic contractions . . . . . . . . . . . . . . . . . . 21

3.4 Functional commutant . . . . . . . . . . . . . . . . 25

4 Quasianalytic contractions in special classes 31

4.1 Analytic contractions . . . . . . . . . . . . . . . . . . . 31

4.2 Bilateral weighted shifts . . . . . . . . . . . . . . 34

5 Spectral behaviour of quasianalytic contractions 39

$\begin{array}{ll}\text { Summary } & 45\end{array}$

Összefoglalás $\quad 49$

$\begin{array}{ll}\text { Acknowledgements } & 53\end{array}$

$\begin{array}{ll}\text { Bibliography } & 54\end{array}$ 


\section{Chapter 1}

\section{Introduction}

The aim of this thesis is to continue the study of contractions, initiated by B. Sz.Nagy and C. Foias and carried on by many researchers, with the hope that our results help to understand the behaviour of bounded linear operators on Hilbert spaces, and to get closer to the solution of the famous invariant and hyperinvariant subspace problems. The dissertation contains two different topics concerning absolutely continuous contractions.

In the first part we study the stability of contractions, we characterize those sequences of bounded analytic functions, which have the property that an absolutely continuous contraction $T$ is stable (that is the powers $T^{n}$ converge to zero in the strong operator topology) if and only if the operators $h_{n}(T)$ converge to zero in the strong operator topology. Our result is extended to polynomially bounded operators too.

In the bigger second part asymptotically non-vanishing contractions are considered, the study of quasianalytic contractions, initiated by L. Kérchy, are continued. These investigations are motivated by the invariant and hyperinvariant subspace problems. Special emphasis is put on the case when the contraction is asymptotically cyclic. New properties of the functional commutant are explored. Analytic contractions and bilateral weighted shifts are discussed as illuminating examples. Last, but not least, we pose, and answer partially, questions in connection with the spectral behaviour of quasianalytic contractions. 


\subsection{Motivation and background}

The investigations included in this dissertation were mainly motivated by the most challenging open problems in the theory of Hilbert spaces and bounded linear operators on them, namely, the well-known invariant and hyperinvariant subspace problems. These are clearly the most fundamental questions concerning the structure of Hilbert space operators, hence it is quite confusing that these problems are still unsolved. In what follows let $\mathcal{L}(\mathcal{H})$ stand for the $C^{*}$-algebra of all bounded linear operators acting on the (complex) Hilbert space $\mathcal{H}$. The Invariant Subspace Problem (ISP) asks the existence of a non-trivial invariant subspace $\mathcal{M} \subset \mathcal{H}$ of an arbitrary operator $T \in \mathcal{L}(\mathcal{H})$, while the Hyperinvariant Subspace Problem (HSP) asks whether there exists a non-trivial hyperinvariant subspace $\mathcal{N} \subset \mathcal{H}$ of an arbitrary non-scalar $T \in \mathcal{L}(\mathcal{H}) \backslash \mathbb{C} I$, i.e., an operator which is not a scalar multiple of the identity operator. The subspace (closed linear manifold) $\mathcal{M} \subset \mathcal{H}$ is invariant for $T$ if $T \mathcal{M}=\{T x: x \in \mathcal{M}\} \subset \mathcal{M}$ holds, and it is non-trivial if $\mathcal{M} \neq\{0\}$ and $\mathcal{M} \neq \mathcal{H}$. The subspace $\mathcal{N} \subset \mathcal{H}$ is hyperinvariant for $T$ if it is invariant for every operator commuting with $T: C \mathcal{N} \subset \mathcal{N}$ whenever $C T=T C$ for an operator $C \in \mathcal{L}(\mathcal{H})$. The $C=T$ case shows that every hyperinvariant subspace for $T$ is invariant for that, and thus, of course, a positive answer for (HSP) would imply a positive answer for (ISP), while a solution of (ISP) into the negative, would be a solution of (HSP) into the negative, too. It is easy to see that the eigenspace corresponding to an eigenvalue of $T$ is always hyperinvariant for $T$, and it is non-trivial if $T$ is non-scalar. Thus, for example, if $\mathcal{H}$ has finite dimension at least two, then (HSP) is solved in the affirmative. On the other hand, if $\mathcal{H}$ is non-separable, then the cyclic subspace, spanned by the orbit $\left\{x, T x, T^{2} x, \ldots\right\}$ of any non-zero vector $x \in \mathcal{H}$, is a non-trivial invariant subspace for $T$.

From now on, throughout the whole thesis, we will assume that $\mathcal{H}$ is a complex, separable, infinite dimensional Hilbert space. In spite of (ISP) and (HSP) are still open in this case, for several classes of operators existence of invariant and hyperinvariant subspaces have been proven. For example, the well-known Spectral Theorem implies that every non-scalar normal operator has a hyperinvariant subspace. We do not have such a nice structure theorem for compact operators, but in the middle of the twentieth century N. Aronszajn and K. T. Smith were able to prove that any compact operator has a non-trivial invariant subspace (see [AS54]). Moreover, in 1973, Lomonosov gave a short proof using the Schauder fixed point theorem that a 
non-scalar operator commuting with a non-zero compact operator has a non-trivial hyperinvariant subspace (see [Lom73]).

One of the most powerful tools, used for examining non-normal operators, is the theory of contractions. A linear operator $T$, acting on a Hilbert space $\mathcal{H}$, is a contraction if $\|T\| \leq 1$ holds. This theory was mainly developed by B. Sz.-Nagy and C. Foias, based on the dilation theorem of Sz.-Nagy, which assigns a unitary operator to the contraction $T$, namely the minimal unitary dilation of $T$.

Theorem 1.1 (Sz.-Nagy's dilation theorem, [Nagy53]). For every contraction $T \in$ $\mathcal{L}(\mathcal{H})$, there exists a unitary operator $U$ acting on a Hilbert space $\mathcal{K}$ containing $\mathcal{H}$ as a subspace, such that

$$
T^{n}=P_{\mathcal{H}} U^{n} \mid \mathcal{H}
$$

holds for every $n \in \mathbb{N}$, where $P_{\mathcal{H}} \in \mathcal{L}(\mathcal{K})$ denotes the orthogonal projection onto $\mathcal{H}$. A unitary operator $U$ satisfying this condition is called a unitary dilation of $T$. Moreover, $U$ can be chosen to be minimal in the sense that

$$
\bigvee_{n \in \mathbb{Z}} U^{n} \mathcal{H}=\mathcal{K}
$$

is fulfilled. Such a minimal dilation is unique up to isomorphism, and thus can be called "the minimal unitary dilation" of $T$.

Considering (ISP) and (HSP) it is sufficient to investigate only contractions, since the invariant and hyperinvariant subspace lattices of an operator $T \in \mathcal{L}(\mathcal{H})$ are the same as of $c T$ for any non-zero complex number $c$. Moreover, it is well-known that any contraction can be uniquely decomposed into the orthogonal sum $T=T_{1} \oplus$ $U_{a} \oplus U_{s}$ of a completely non-unitary (c.n.u.) contraction $T_{1}$, an absolutely continuous (a.c.) unitary operator $U_{a}$, and a singular unitary operator $U_{s}$ (see [NFBK], Theorem I.3.2 and [Hal51]) . We recall that a contraction is c.n.u. if it is not unitary on any of its non-zero reducing subspaces, and that a unitary operator is a.c. or singular if its spectral measure is a.c. or singular with respect to Lebesgue measure on the unit circle. Applying the Lifting Theorem of Sz.-Nagy and Foias it can be easily verified that the hyperinvariant subspace lattice of $T$ splits into the direct sum Hlat $T=$ Hlat $\left(T_{1} \oplus U_{a}\right) \oplus$ Hlat $U_{s}$ (see [NFBK, Theorem II.2.3] and [Dou60, Corollary 5.1 and Theorem 3]). Thus, if the singular unitary component $U_{s}$ is non-zero (and $T$ is non-scalar), then $T$ has a non-trivial hyperinvariant subspace. In the sequel, mostly, we will assume that the contraction $T$ is absolutely continuous, i.e., its 
singular unitary part is zero. For such contractions, by the aid of the usual functional calculus (operating with the bounded measurable functions on the unit circle $\mathbb{T}$ ) for the minimal unitary dilation $U$ of $T$, we can introduce the so-called Sz.-Nagy-Foias functional calculus $\Phi_{T}$ for $T$ :

$$
\Phi_{T}: H^{\infty} \rightarrow \mathcal{L}(\mathcal{H}), f \mapsto f(T):=P_{\mathcal{H}} f(U) \mid \mathcal{H}
$$

where $H^{\infty}$ denotes the Hardy space of all bounded analytic functions on the open unit disc $\mathbb{D}$ (what can be identified with the space of bounded measurable functions on the unit circle $\mathbb{T}$ with zero Fourier coefficients of negative indices). This $\Phi_{T}$ is a contractive, unital algebra-homomorphism, which is continuous in the weak-* topologies and satisfies the condition $T=\Phi_{T}(\chi)=\chi(T)$, where $\chi(z)=z$ denotes the identical function.

Another important tool in the study of a contraction $T$ is its unitary asymptote. The pair $(X, V)$ is a unitary asymptote of $T$ if $V$ is a unitary operator acting on a Hilbert space $\mathcal{K}$ and $X: \mathcal{H} \rightarrow \mathcal{K}$ is a linear transformation satisfying the conditions $\vee_{n=1}^{\infty} V^{-n} X \mathcal{H}=\mathcal{K},\|X h\|=\lim _{n \rightarrow \infty}\left\|T^{n} h\right\|$ for every $h \in \mathcal{H}$, and $X T=V X$. For further properties of unitary asymptotes we refer to [Kér13] and [NFBK, Chapter IX]. It is easy to see that the nullspace of $X$ is hyperinvariant for $T$, it is the so-called stable subspace of $T$ :

$$
\mathcal{H}_{0}(T)=\left\{h \in \mathcal{H}: \lim _{n \rightarrow \infty}\left\|T^{n} h\right\|=0\right\}
$$

Considering the asymptotic behaviour of contractions Sz.-Nagy and Foias introduced the following classes:

- $T \in C_{0}$. if $\mathcal{H}_{0}(T)=\mathcal{H}$, that is, when $T^{n} \rightarrow 0$ in the strong operator topology (SOT). In this case $T$ is called stable, while a non-stable $T$ is usually called asymptotically non-vanishing.

- $T \in C_{1}$. if $\mathcal{H}_{0}(T)=\{0\}$. Contractions of this type are called asymptotically strongly non-vanishing.

- $T \in C_{.0}$ if $T^{*} \in C_{0}$;

- $T \in C_{\cdot 1}$ if $T^{*} \in C_{1}$;

- $C_{i j}=C_{i \cdot} \cap C_{\cdot j}(i, j=0,1)$. 
Obviously, if $T \notin C_{00} \cup C_{01} \cup C_{10} \cup C_{11}$, then $T$ has a non-trivial hyperinvariant subspace, namely $\mathcal{H}_{0}(T)$ or $\mathcal{H}_{0}\left(T^{*}\right)^{\perp}$. Moreover, Sz.-Nagy and Foias showed that Hlat $T$ is non-trivial in the case of a non-scalar operator $T \in C_{11}$, too (see [NFBK, Theorem II.5.4]). On the other hand, (ISP) and (HSP) are still open in the classes $C_{00}, C_{10}$, and $C_{01}$. Actually, considering $T /(2\|T\|)$, it can be seen that these problems in $C_{00}$ are equivalent to the general questions. The remaining classes $C_{10}$ and $C_{01}$ are the adjoints of each other, hence it is enough to study the class $C_{10}$, in which class (ISP) and (HSP) can be reduced to special classes of quasianalytic contractions. In Chapter 3-5 we will examine these kind of contractions. Our basic reference in connection with the theory of contractions is [NFBK].

\subsection{Thesis outline}

In Chapter 2 we study stability properties of contractions and polynomially bounded operators. In Section 2.1 we characterize those sequences $\left\{h_{n}\right\}_{n=1}^{\infty}$ of bounded analytic functions, which can serve to test the stability of an a.c. contraction, namely, satisfying the condition that $h_{n}(T) \rightarrow 0$ (SOT) if and only if $T \in C_{0}$. This answers a question of M. Dritschel. We prove some connected results too. In Section 2.2 analogous questions for polynomially bounded operators are examined.

In the remaining chapters we investigate special types of asymptotically nonvanishing contractions, namely, quasianalytic contractions. In the beginning of Chapter 3, namely, in Section 3.1 we introduce local version of the quasianalytic spectral set and exhibit its connection with the residual set. In Section 3.2 the fundamental properties of quasianalytic contractions are summarized including their asymptotic behaviour. Asymptotically cyclic quasianalytic contractions are studied in Section 3.3, where equivalent conditions are given for the existence of a non-trivial hyperinvariant subspace. For such a contraction $T$ the commutant $\{T\}^{\prime}$ can be identified with a function algebra $\mathcal{F}(T)$, the so-called functional commutant. Answering a question posed in [Kér11] we show in Section 3.4 that $\mathcal{F}(T)$ can be a pre-Douglas algebra only in the case when $\mathcal{F}(T)=H^{\infty}$. We prove also similarity invariance of $\mathcal{F}(T)$ and detect its representation in the functional model.

Chapter 4 is devoted to special classes of operators, where quasianalytic contractions naturally arise. Namely, we study analytic contractions in Section 4.1 and bilateral weighted shifts in Section 4.2.

At last, Chapter 5 contains some questions, and partial answers in connection 
with the spectral behaviour of quasianalytic contractions.

The main results and their proofs given here are essentially the same as in the following three papers, which provide the material of this dissertation:

- L. KÉRChy and A. Szalai, Characterization of stability of contractions, Acta Sci. Math. (Szeged), 79 (2013), 325-332.

- L. KérChy and A. Szalai, Asymptotically cyclic quasianalytic contractions, Studia Math., 223 (2014), 53-75.

- L. KÉRChy and A. Szalai, Spectral behaviour of quasianalytic contractions, Proc. Amer. Math. Soc., accepted. 


\section{Chapter 2}

\section{Stability results}

In this chapter we study some stability properties of contractions and polynomially bounded operators. In Section 2.1 we characterize those sequences $\left\{h_{n}\right\}_{n=1}^{\infty}$ of bounded analytic functions, which can serve to test the stability of an a.c. contraction, namely, satisfying the condition that $h_{n}(T) \rightarrow 0$ (SOT) if and only if $T \in C_{0}$. This answers a question of M. Dritschel. We prove some connected results too. In Section 2.2 analogous questions for polynomially bounded operators are examined.

\subsection{Contractions}

Let $H^{\infty}$ denote the Hardy space of bounded analytic functions defined on the open unit disc $\mathbb{D}$. We recall that for any $h \in H^{\infty}$ the radial $\operatorname{limit} \lim _{r \rightarrow 1-} h(r \zeta)$ exists for almost every $\zeta \in \mathbb{T}$; the limit function will also be denoted by $h$. In connection with the basic properties of $H^{\infty}$, we refer to [Hof88] and Chapter III of [NFBK]. The following property plays crucial role in the characterization of stability.

Definition 2.1. A sequence of bounded analytic functions $\left\{h_{n}\right\}_{n=1}^{\infty} \subset H^{\infty}$ converges to zero exclusively on $\mathbb{D}$, if

(i) $\lim _{n \rightarrow \infty} h_{n}(z)=0$ for all $z \in \mathbb{D}$,

(ii) $\sup \left\{\left\|h_{n}\right\|_{\infty}: n \in \mathbb{N}\right\}<\infty$,

(iii) $\lim \sup _{n \rightarrow \infty}\left\|\chi_{\alpha} h_{n}\right\|_{2}>0$ for every Borel set $\alpha \subset \mathbb{T}$ of positive measure, where $\chi_{\alpha}$ is the characteristic function of $\alpha$.

Remark 2.2. (a) The conditions (i) and (ii) together mean that $\left\{h_{n}\right\}_{n=1}^{\infty}$ converges to zero in the weak-* topology. 
(b) Because of (ii), condition (iii) can be replaced by

(iii*) $\limsup _{n \rightarrow \infty} m\left(\left\{\zeta \in \alpha:\left|h_{n}(\zeta)\right|>\varepsilon\right\}\right)>0$ for every $\alpha \subset \mathbb{T}$ of positive measure with some $\varepsilon>0$ (depending on $\alpha$ ).

(That is $\left\{h_{n}\right\}_{n=1}^{\infty}$ does not converge to zero in measure on $\alpha$.)

(c) If $\liminf _{n \rightarrow \infty}\left|h_{n}(\zeta)\right|>0$ for almost every $\zeta \in \mathbb{T}$ then (iii) holds, and (iii) with (ii) imply that $\limsup _{n \rightarrow \infty}\left|h_{n}(\zeta)\right|>0$ for a.e. $\zeta \in \mathbb{T}$. In particular, if we suppose that the limit $\lim _{n \rightarrow \infty}\left|h_{n}(\zeta)\right|$ exists for a.e. $\zeta \in \mathbb{T}$, then condition (iii) can be replaced by the property, that $\lim _{n \rightarrow \infty}\left|h_{n}(\zeta)\right|>0$ for a.e. $\zeta \in \mathbb{T}$.

Example 2.3. (a) According to the last remark, any uniformly bounded sequence $h_{n} \subset H^{\infty}$, converging to zero in the open unit disc and to non-zero almost everywhere on the unit circle, converges to zero exclusively on $\mathbb{D}$.

(b) For example, we get a sequence of this type, if we set a non-constant inner function $u$ and consider the sequence $h_{n}=u^{n}$.

(c) Another special example is $h_{n}=\chi^{n+1}-\chi^{n}$.

Definition 2.4. A sequence of bounded analytic functions $\left\{h_{n}\right\}_{n=1}^{\infty} \subset H^{\infty}$ is a test sequence of stability for a.c. contractions if for every a.c. contraction $T$ the condition $T^{n} \rightarrow 0$ (SOT) holds exactly when $h_{n}(T) \rightarrow 0$ (SOT).

The main result of this chapter is the following statement.

Theorem 2.5. A sequence of bounded analytic functions $\left\{h_{n}\right\}_{n=1}^{\infty} \subset H^{\infty}$ is a test sequence of stability for a.c. contractions if and only if it converges to zero exclusively on $\mathbb{D}$.

Proof. For the proof of necessity let us assume that $\left\{h_{n}\right\}_{n=1}^{\infty}$ is a test sequence of stability for a.c. contractions. Let $S \in \mathcal{L}\left(H^{2}\right), S f=\chi f$ be the unilateral shift of multiplicity one $\left(\chi(z)=z\right.$ and $H^{2}$ is the analytic subspace of $\left.L^{2}(\mathbb{T})\right)$. Then $S^{* n} \rightarrow 0(\mathrm{SOT})$ and hence $h_{n}\left(S^{*}\right) \rightarrow 0(\mathrm{SOT})$. It is known that $f(\lambda)=\left\langle f, k_{\lambda}\right\rangle$ for every $f \in H^{2}$ and $\lambda \in \mathbb{D}$, where $k_{\lambda}(z)=(1-\bar{\lambda} z)^{-1}$ is the Cauchy kernel. Since $S^{*} k_{\lambda}=S^{*} \sum_{n=0}^{\infty} \bar{\lambda}^{n} \chi^{n}=\bar{\lambda} k_{\lambda}$, it follows that $h_{n}\left(S^{*}\right) k_{\lambda}=h_{n}(\bar{\lambda}) k_{\lambda}$ and so $h_{n}(\bar{\lambda}) \rightarrow 0$ for all $\lambda \in \mathbb{D}$, that is (i) holds.

It can be easily seen that $\left\|h\left(S^{*}\right)\right\|=\|h\|_{\infty}$ for all $h \in H^{\infty}$. Indeed,

$$
\|h\|_{\infty} \geq\left\|h\left(S^{*}\right)\right\| \geq \frac{\left\|h\left(S^{*}\right) k_{\lambda}\right\|_{2}}{\left\|k_{\lambda}\right\|_{2}}=|h(\bar{\lambda})| \quad(\lambda \in \mathbb{D}) .
$$


The Banach-Steinhaus Theorem shows that $\sup _{n}\left\|h_{n}\right\|_{\infty}=\sup _{n}\left\|h_{n}\left(S^{*}\right)\right\|<\infty$, and so (ii) holds.

Let $\alpha \subset \mathbb{T}$ be a Borel set with $m(\alpha)>0$, and let us consider the Hilbert space $L^{2}(\alpha)=\chi_{\alpha} L^{2}(\mathbb{T})$. The multiplication operator $M_{\alpha} \in \mathcal{L}\left(L^{2}(\alpha)\right), M_{\alpha} g=\chi g$ is an a.c. unitary operator, and $h\left(M_{\alpha}\right) g=h g$ for every $h \in H^{\infty}$ and $g \in L^{2}(\alpha)$. Since $M_{\alpha}^{n} \nrightarrow \rightarrow 0(\mathrm{SOT})$ hence $h_{n}\left(M_{\alpha}\right) \not \rightarrow 0(\mathrm{SOT})$. Assume that $\left\|\chi_{\alpha} h_{n}\right\|_{2}=\left\|h_{n}\left(M_{\alpha}\right) \mathbf{1}\right\|_{2} \rightarrow$ 0 . Then $\left\|h_{n}\left(M_{\alpha}\right) \varphi\right\|_{2}=\left\|\varphi\left(M_{\alpha}\right) h_{n}\left(M_{\alpha}\right) \mathbf{1}\right\|_{2} \rightarrow 0$ for all $\varphi \in L^{\infty}(\alpha)$, and thus, by (ii), we infer that $h_{n}\left(M_{\alpha}\right) \rightarrow 0$ (SOT) which is a contradiction. Consequently (iii) holds.

Now we turn to the sufficiency part; so let us assume that $\left\{h_{n}\right\}_{n=1}^{\infty}$ converges to zero exclusively on $\mathbb{D}$. Setting any stable contraction $T$, there exists an invariant subspace $\mathcal{M} \in$ Lat $S_{\infty}^{*}$ such that $T$ is unitarily equivalent to $S_{\infty}^{*} \mid \mathcal{M}$. (Here $S_{\infty}^{*}=$ $S^{*} \oplus S^{*} \oplus \ldots$; see [Foi63].) Property (i) implies that $\left\|h_{n}\left(S^{*}\right) k_{\lambda}\right\| \rightarrow 0$ for all $\lambda \in \mathbb{D}$, and it is known that $\vee\left\{k_{\lambda}: \lambda \in \mathbb{D}\right\}=H^{2}$. But $\left\{h_{n}\left(S^{*}\right)\right\}_{n=1}^{\infty}$ is bounded by (ii) and so $h_{n}\left(S^{*}\right) \rightarrow 0$ (SOT), whence $h_{n}\left(S_{\infty}^{*}\right) \rightarrow 0$ and $h_{n}(T) \rightarrow 0$ (SOT) follow.

It is left to prove that $h_{n}(T) \not \rightarrow 0$ (SOT), whenever $T$ is not stable. If $T$ is a non-stable a.c. contraction, then it can be written in the form

$$
T=\left[\begin{array}{cc}
T_{0} & * \\
0 & T_{1}
\end{array}\right] \in \mathcal{L}\left(\mathcal{H}=\mathcal{H}_{0} \oplus \mathcal{H}_{1}\right),
$$

where $T_{0} \in C_{0}, T_{1} \in C_{1}$. and $\mathcal{H}_{1} \neq\{0\}$. Then

$$
h(T)=\left[\begin{array}{cc}
h\left(T_{0}\right) & * \\
0 & h\left(T_{1}\right)
\end{array}\right]
$$

for any $h \in H^{\infty}$. Now let us assume that $h_{n}(T) \rightarrow 0$ (SOT). This implies that $h_{n}\left(T_{1}\right) \rightarrow 0(\mathrm{SOT})$. Let $\left(X_{1}, V_{1}\right)$ be a unitary asymptote of $T_{1}$, where $V_{1}$ is an a.c. unitary operator and $X_{1}$ is an injective transformation intertwining $T_{1}$ with $V_{1}$ : $X_{1} T_{1}=V_{1} X_{1}$; see Section IX.1 in [NFBK]. Then $h_{n}\left(V_{1}\right) X_{1}=X_{1} h_{n}\left(T_{1}\right) \rightarrow 0$ (SOT) and so $\left\|h_{n}\left(V_{1}\right) y\right\| \rightarrow 0$ for all $y \in X_{1} \mathcal{H}_{1}$. Since $\left\|h_{n}\left(V_{1}\right)\right\| \leq\left\|h_{n}\right\|_{\infty} \leq \sup _{k}\left\|h_{k}\right\|_{\infty}<$ $\infty$, it follows that $\left\|h_{n}\left(V_{1}\right) y\right\| \rightarrow 0$ for all $y \in\left(X_{1} \mathcal{H}_{1}\right)^{-}$. Since $V_{1}$ is the minimal unitary extension of the isometry $V_{1} \mid\left(X_{1} V_{1}\right)^{-}$, we can easily infer that $h_{n}\left(V_{1}\right) \rightarrow 0$ (SOT). Then $\left\|\chi_{\alpha} h_{n}\right\|_{2} \rightarrow 0$ holds for the Borel set $\alpha$ given so that $\chi_{\alpha} d m$ is equivalent to the spectral measure of $V_{1}$. This contradicts (iii), thus $h_{n}(T) \not \rightarrow 0$ (SOT).

A part of the proof above yields the following proposition. 
Proposition 2.6. Let $\left\{h_{n}\right\}_{n=1}^{\infty} \subset H^{\infty}$. Then $h_{n}(T) \rightarrow 0$ (SOT) for every stable contraction $T$ if and only if $\left\{h_{n}\right\}_{n=1}^{\infty}$ satisfies the conditions (i) and (ii).

A well-known property of the Sz.-Nagy-Foias functional calculus is that $h_{n}(T) \rightarrow$ 0 (SOT) for every a.c. contraction T, whenever $\left\{h_{n}\right\}_{n=1}^{\infty}$ boundedly converges to zero a.e. on $\mathbb{T}$ (see [NFBK, Chapter III]). The next proposition shows that the necessary and sufficient condition is weaker.

Proposition 2.7. Let $\left\{h_{n}\right\}_{n=1}^{\infty} \subset H^{\infty}$. Then $h_{n}(T) \rightarrow 0$ (SOT) for every a.c. contraction T exactly when $\left\{h_{n}\right\}_{n=1}^{\infty}$ is a bounded sequence in $H^{\infty}$ and $\lim _{n \rightarrow \infty}\left\|h_{n}\right\|_{2}=$ 0 .

Proof. First let us suppose that $\lim _{n \rightarrow \infty}\left\|h_{n}\right\|_{2}=0$ holds for the bounded sequence $\left\{h_{n}\right\}_{n=1}^{\infty}$, and let us consider an a.c. contraction $T$. Let $U$ be the minimal unitary dilation of $T$ with spectral measure $E$. Then for any $x \in \mathcal{H}$ we have

$$
\left\|h_{n}(T) x\right\|^{2} \leq\left\|h_{n}(U) x\right\|^{2}=\int_{\mathbb{T}}\left|h_{n}\right|^{2} f_{x} \mathrm{~d} m
$$

where $0 \leq f_{x}=\mathrm{d} E_{x, x} / \mathrm{d} m \in L^{1}(\mathbb{T})$. Let $\varepsilon>0$ be fixed. Choosing $N$ large enough, we have $\int_{\beta_{N}} f_{x} d m<\varepsilon /\left(2 M^{2}\right)$, where $\beta_{N}=\left\{\zeta \in \mathbb{T}: f_{x}(\zeta) \geq N\right\}$ and $M=\sup \left\{\left\|h_{n}\right\|_{\infty}: n \in \mathbb{N}\right\}$. Hence

$$
\int_{\mathbb{T}}\left|h_{n}\right|^{2} f_{x} \mathrm{~d} m \leq M^{2} \int_{\beta_{N}} f_{x} \mathrm{~d} m+N \int_{\mathbb{T} \backslash \beta_{N}}\left|h_{n}\right|^{2} \mathrm{~d} m \leq \frac{\varepsilon}{2}+N\left\|h_{n}\right\|_{2}^{2}<\varepsilon,
$$

if $n$ is large enough. Therefore $h_{n}(T) \rightarrow 0$ (SOT).

Now let us suppose that $h_{n}(T) \rightarrow 0$ (SOT) for every a.c. contraction T. In the proof of Theorem 2.5 we have already seen that if $h_{n}\left(S^{*}\right) \rightarrow 0$ (SOT) then $\left\{h_{n}\right\}_{n=1}^{\infty}$ is a bounded sequence. On the other hand, if we consider the bilateral shift $M \in \mathcal{L}\left(L^{2}(\mathbb{T})\right), M g=\chi g$ and the constant function $\mathbf{1} \in L^{2}(\mathbb{T})$, then we obtain that

$$
\int_{\mathbb{T}}\left|h_{n}\right|^{2} \mathrm{~d} m=\left\|h_{n}(M) \mathbf{1}\right\|_{2}^{2} \rightarrow 0
$$

Remark 2.8. We may consider nets instead of sequences, and we can define exclusive convergence and testing property in a similar way than in the case of sequences. The proof given before shows that if a net converges exclusively to zero on $\mathbb{D}$ than it is a test net for a.c. contractions. However, considering the reverse implication we get in the obstacle that convergent nets are not necessarily bounded, and so the Banach-Steinhaus Theorem cannot be applied. 


\subsection{Polynomially bounded operators}

Let us denote by $\mathcal{P}(\mathbb{T})$ the set of analytic polynomials on $\mathbb{T}$, and by $A=A(\mathbb{T})$ the disc algebra, i.e., the closure of $\mathcal{P}(\mathbb{T})$ in the Banach space $C(\mathbb{T})$ of continuous functions on $\mathbb{T}$. An operator $T \in \mathcal{L}(\mathcal{H})$ is called polynomially bounded if there exists a real number $K_{T}$ such that $\|p(T)\| \leq K_{T}\|p\|$ for all $p \in \mathcal{P}(\mathbb{T})$, where $\|p\|=\max \{|p(\zeta)|: \zeta \in \mathbb{T}\}$. For a polynomially bounded operator $T$, the mapping $\Phi_{T, 0}: \mathcal{P}(\mathbb{T}) \rightarrow \mathcal{L}(\mathcal{H}), p \mapsto p(T)$ is a bounded algebra-homomorphism which extends continuously to the disc algebra: $\Phi_{T, 1}: A \rightarrow \mathcal{L}(\mathcal{H}), f \mapsto f(T)$. Polynomially bounded operators were studied by W. Mlak in a series of papers using 'elementary measures'. Here we recall some basic facts from his works. For any $x, y \in \mathcal{H}$ let us consider the continuous linear functional $\varphi_{x, y}: \mathcal{L}(\mathcal{H}) \rightarrow \mathbb{C}$ defined by $\varphi_{x, y}(C)=\langle C x, y\rangle$. By the Hahn-Banach Theorem $\varphi_{x, y} \circ \Phi_{T, 1}: A \rightarrow \mathbb{C}$ can be extended to a bounded linear functional $\Psi_{x, y}: C(\mathbb{T}) \rightarrow \mathbb{C}$. By the Riesz Representation Theorem there exists a unique regular complex Borel measure $\mu_{x, y}$ on $\mathbb{T}$ such that $\Psi_{x, y}(f)=\int_{\mathbb{T}} f \mathrm{~d} \mu_{x, y}$ for all $f \in C(\mathbb{T})$, in particular for all $f \in A$. Let us denote by $M(T, x, y)$ the set of such representing measures. If $\mu, \nu \in M(T, x, y)$ then $\mu-\nu \perp A$, hence $\mu-\nu=h \mathrm{~d} m$ for some $h \in H_{0}^{1}$ by the F \& M. Riesz theorem; thus $M(T, x, y)=\left\{\mu_{x, y}+h \mathrm{~d} m: h \in H_{0}^{1}\right\}$. (If $T$ is a contraction then $\mu_{x, y}$ can be chosen to be the localization of the spectral measure of the unitary dilation of $T$.) The polynomially bounded operator $T$ is called absolutely continuous if for every $x, y \in \mathcal{H}$ there exists a measure $\mu \in M(T, x, y)$ which is absolutely continuous with respect to the Lebesgue measure. $T$ is singular if for any pair $x, y \in \mathcal{H}$ there is a measure $\mu \in M(T, x, y)$ which is singular to $m$. Every polynomially bounded operator $T$ can be uniquely decomposed into the direct sum $T=T_{a} \dot{+} T_{s}$ of an a.c. polynomially bounded operator $T_{a}$ and a singular polynomially bounded operator $T_{s}$ (see [Mla73]). We say that an operator $T \in \mathcal{L}(\mathcal{H})$ admits an $H^{\infty}$-functional calculus if there is a weak-* continuous, unital algebra-homomorphism $\Phi_{T}: H^{\infty} \rightarrow \mathcal{L}(\mathcal{H})$ such that $\Phi_{T}(\chi)=T$. If there exists such a $\Phi_{T}$, then it is bounded and unique. It turns out that $T$ admits an $H^{\infty}$-functional calculus exactly when $T$ is a.c. polynomially bounded operator (see p. 68 in [Mla74a]). In this case $\Phi_{T} \mid A=\Phi_{T, 1}$.

We proceed with testing the stability of a.c. polynomially bounded operators.

Definition 2.9. A sequence of bounded analytic functions $\left\{h_{n}\right\}_{n=1}^{\infty} \subset H^{\infty}$ is a test sequence of stability for a.c. polynomially bounded operators if for every a.c. polynomially bounded operator $T \in \mathcal{L}(\mathcal{H})$ the condition $T^{n} \rightarrow 0$ (SOT) holds 
exactly when $h_{n}(T) \rightarrow 0(\mathrm{SOT})$.

Note that, in principle, a test sequence for a.c. contractions is not necessarily a test sequence for a.c. polynomially bounded operators. Nevertheless, we can prove the following theorem.

Theorem 2.10. A sequence of bounded analytic functions $\left\{h_{n}\right\}_{n=1}^{\infty} \subset H^{\infty}$ is a test sequence of stability for a.c. polynomially bounded operators if and only if $\left\{h_{n}\right\}_{n=1}^{\infty}$ converges to zero exclusively on $\mathbb{D}$.

Proof. The necessity part follows from Theorem 2.5 since a test sequence of stability for a.c. polynomially bounded operators is a test sequence of stability for a.c. contractions too. For the proof of sufficiency let us suppose that $\left\{h_{n}\right\}_{n=1}^{\infty}$ converges to zero exclusively on $\mathbb{D}$, and let $T \in \mathcal{L}(\mathcal{H})$ be an a.c. polynomially bounded operator such that $T^{n} \rightarrow 0$ (SOT). In view of (i) and (ii) the Vitali-Montel Theorem yields that $h_{n} \rightarrow 0$ locally uniformly on $\mathbb{D}$, and so, for every $k \in \mathbb{N}, h_{n}^{(k)} \rightarrow 0$ locally uniformly on $\mathbb{D}$ by the Weierstrass Theorem. Let us consider the expansion $h_{n}=\sum_{k=0}^{\infty} c_{n, k} \chi^{k}$ where $c_{n, k}=h_{n}^{(k)}(0) / k$ ! are the Taylor coefficients. We have

$$
h_{n}=\sum_{k=0}^{N-1} c_{n, k} \chi^{k}+\chi^{N} \sum_{k=N}^{\infty} c_{n, k} \chi^{k-N}=f_{n, N}+\chi^{N} g_{n, N} .
$$

By the Maximum Principle $\left\|g_{n, N}\right\|_{\infty} \leq\left\|h_{n}\right\|_{\infty}+\left\|f_{n, N}\right\|_{\infty} \leq M+\left\|f_{n, N}\right\|_{\infty}$, and it is clear that $\lim _{n \rightarrow \infty}\left\|f_{n, N}\right\|_{\infty}=0$ for any $N \in \mathbb{N}$. Let $x \in \mathcal{H}$ and $\varepsilon>0$ be fixed. Then

$$
\begin{aligned}
\left\|h_{n}(T) x\right\| & \leq\left\|f_{n, N}(T) x\right\|+\left\|g_{n, N}(T) T^{N} x\right\| \\
& \leq\left\|\Phi_{T}\right\|\left\|f_{n, N}\right\|_{\infty}\|x\|+\left\|\Phi_{T}\right\|\left\|g_{n, N}\right\|_{\infty}\left\|T^{N} x\right\| .
\end{aligned}
$$

We can choose $N$ so that $\left\|T^{N} x\right\|<\varepsilon$. Fixing $N$ in this way, there exists $\nu \in \mathbb{N}$ such that $\left\|f_{n, N}\right\|_{\infty}<\varepsilon$ for every $n>\nu$. Therefore, $\left\|h_{n}(T) x\right\| \leq\left\|\Phi_{T}\right\| \varepsilon\|x\|+\left\|\Phi_{T}\right\|(M+\varepsilon) \varepsilon$ holds for all $n>\nu$, and so $\lim _{n \rightarrow \infty}\left\|h_{n}(T) x\right\|=0$.

Now suppose that $T^{n} \nrightarrow \nrightarrow 0$ (SOT). Then there exist an a.c. (non-zero) isometry $V$ and a bounded linear transformation $X$ with dense range, such that $X T=V X$; see [Kér89]. If $h_{n}(T) \rightarrow 0$ (SOT), then $h_{n}(V) \rightarrow 0$ (SOT) and this contradicts (iii).

We conclude this chapter by formulating a statement about the stability of singular polynomially bounded operators. 
Proposition 2.11. Let $\left\{h_{n}\right\}_{n=1}^{\infty} \subset A$ be a bounded sequence in the disc algebra. Then $h_{n}(T) \rightarrow 0$ (SOT) for every singular polynomially bounded operator $T$ if and only if $\lim _{n \rightarrow \infty} h_{n}(\zeta)=0$ for every $\zeta \in \mathbb{T}$. In that case $h_{n}(T) \rightarrow 0$ (SOT) for every polynomially bounded operator $T$.

Proof. It is known that any singular polynomially bounded operator $T$ is similar to a singular unitary operator $U$, that is $T=X^{-1} U X$ with some boundedly invertible operator $X$ (see [Mla74b]). Suppose that $\lim _{n \rightarrow \infty} h_{n}(\zeta)=0$ for a.e. $\zeta \in \mathbb{T}$. Then, for every $y \in \mathcal{H}$, we have

$$
\left\|h_{n}(U) y\right\|^{2}=\int_{\mathbb{T}}\left|h_{n}\right|^{2} \mathrm{~d} E_{y, y} \rightarrow 0
$$

by Lebesgue's Dominated Convergence Theorem. The inequality

$$
\begin{aligned}
\left\|h_{n}(T) x\right\|^{2} & =\left\|h_{n}\left(X^{-1} U X\right) x\right\|^{2}=\left\|X^{-1} h_{n}(U) X x\right\|^{2} \\
& \leq\left\|X^{-1}\right\|^{2}\left\|h_{n}(U) X x\right\|^{2}
\end{aligned}
$$

shows that $h_{n}(T) \rightarrow 0(\mathrm{SOT})$.

If $T$ is an arbitrary polynomially bounded operator, then we decompose it to the direct $\operatorname{sum} T=T_{a} \dot{+} T_{s}$ of an a.c. and a singular polynomially bounded operator. For the singular component we apply the previous result, while for the a.c. component we can apply the proof of Theorem 2.10, since our conditions imply that $h_{n} \rightarrow 0$ locally uniformly on $\mathbb{D}$. Hence $h_{n}(T)=h_{n}\left(T_{a}\right) \dot{+} h_{n}\left(T_{s}\right) \rightarrow 0$ (SOT).

Now let us suppose that $h_{n}(T) \rightarrow 0$ (SOT) for every singular polynomially bounded operator $T$. If we consider the operator $\lambda I(\lambda \in \mathbb{T})$ then we obtain that $\left|h_{n}(\lambda)\right|^{2}\|x\|^{2}=\left\|h_{n}(\lambda I) x\right\|^{2} \rightarrow 0$. The proof is complete. 


\section{Chapter 3}

\section{Hyperinvariant subspaces of quasianalytic contractions}

In this chapter we investigate special types of asymptotically non-vanishing contractions, namely, quasianalytic contractions. In the beginning, namely, in Section 3.1 we introduce local version of the quasianalytic spectral set and exhibit its connection with the residual set. In Section 3.2 the fundamental properties of quasianalytic contractions are summarized including their asymptotic behaviour. Asymptotically cyclic quasianalytic contractions are studied in Section 3.3, where equivalent conditions are given for the existence of a non-trivial hyperinvariant subspace. For such a contraction $T$ the commutant $\{T\}^{\prime}$ can be identified with a function algebra $\mathcal{F}(T)$, the so-called functional commutant. Answering a question posed in [Kér11] we show in Section 3.4 that $\mathcal{F}(T)$ can be a pre-Douglas algebra only in the case when $\mathcal{F}(T)=H^{\infty}$. We prove also similarity invariance of $\mathcal{F}(T)$ and detect its representation in the functional model.

\subsection{Local quasianalytic spectral set}

Let $T \in \mathcal{L}(\mathcal{H})$ be an a.c. contraction and let $(X, V)$ be a unitary asymptote of $T$. It is known that $V \in \mathcal{L}(\mathcal{K})$ is an a.c. unitary operator, that is the spectral measure $E$ of $V$ is a.c. with respect to the normalized Lebesgue measure $m$ on the unit circle $\mathbb{T}$. The residual set $\omega(T)$ of $T$ is the measurable support of $E$, which means that $E(\alpha)=0$ if and only if $m(\alpha \cap \omega(T))=0$. For any $x, y \in \mathcal{H}, w_{x, y} \in L^{1}(\mathbb{T})$ is the asymptotic density function of $T$ at $x$ and $y: E_{X x, X y}=w_{x, y} \mathrm{~d} m$. The measurable $\omega(T, x)=\left\{\zeta \in \mathbb{T}: w_{x, x}(\zeta)>0\right\}$ is the local residual set of $T$ at $x$. (It is easy to 
check that $w_{x, y}$ and $\omega(T, x)$ are independent of the special choice of $(X, V)$.) It is worth mentioning that $\mathcal{H}_{\omega}(T)=\{x \in \mathcal{H}: \omega(T, x)=\omega(T)\}$ is a dense $G_{\delta^{-}}$set in $\mathcal{H}$ (see Lemma IX.2.15 in [NFBK]).

We recall the notion of another spectral invariant, defined by the Sz.Nagy-Foias functional calculus $\Phi_{T}$ for $T$. This calculus is monotone in the sense that $\|f(T) x\| \leq$ $\|g(T) x\|$ for every $x \in \mathcal{H}$ (in notation: $f(T) \stackrel{a}{\prec} g(T)$ ) whenever $|f(z)| \leq|g(z)|$ for every $z$ in the unit disc $\mathbb{D}$ (in notation: $f \stackrel{a}{\prec} g$ ). Given a decreasing sequence $F=\left\{f_{n}\right\}_{n=1}^{\infty}$ in $H^{\infty}\left(f_{n+1} \stackrel{a}{\prec} f_{n}\right.$ for every $\left.n\right)$, let us consider the limit function $\varphi_{F}$ on $\mathbb{T}$, defined by $\varphi_{F}(\zeta)=\lim _{n \rightarrow \infty}\left|f_{n}(\zeta)\right|$ for a.e. $\zeta \in \mathbb{T}$, and the measurable set $N_{F}=\left\{\zeta \in \mathbb{T}: \varphi_{F}(\zeta)>0\right\}$. Then the sequence $F(T)=\left\{f_{n}(T)\right\}_{n=1}^{\infty}$ of operators is also decreasing $\left(f_{n+1}(T) \stackrel{a}{\prec} f_{n}(T)\right.$ for every $\left.n\right)$ and the set

$$
\mathcal{H}_{0}(T, F)=\left\{x \in \mathcal{H}: \lim _{n \rightarrow \infty}\left\|f_{n}(T) x\right\|=0\right\}
$$

of stable vectors for $F(T)$ is a hyperinvariant subspace of $T$. For measurable subsets $\alpha$ and $\beta$ of $\mathbb{T}$, we write $\alpha=\beta, \alpha \neq \beta$ and $\alpha \subset \beta$ if $m(\alpha \triangle \beta)=0, m(\alpha \triangle \beta)>0$ and $m(\alpha \backslash \beta)=0$ respectively, that is when $\chi_{\alpha}=\chi_{\beta}, \chi_{\alpha} \neq \chi_{\beta}$ and $\chi_{\alpha} \leq \chi_{\beta}$ hold for the corresponding characteristic functions as elements of the Banach space $L^{1}(\mathbb{T})$. We say that $T$ is quasianalytic on a measurable subset $\alpha$ of $\mathbb{T}$ at a vector $x \in \mathcal{H}$ if $x \notin \mathcal{H}_{0}(T, F)$ whenever $F$ is non-vanishing on $\alpha$, that is $N_{F} \cap \alpha \neq \emptyset$. Let $\mathcal{A}(T, x)$ be the system of sets $\alpha$ with this property and set $a(T, x)=\sup \{m(\alpha): \alpha \in \mathcal{A}(T, x)\}$. Taking a sequence $\left\{\alpha_{n}\right\}_{n=1}^{\infty}$ in $\mathcal{A}(T, x)$ so that $\lim _{n \rightarrow \infty} m\left(\alpha_{n}\right)=a(T, x)$, it is easy to see that $\pi(T, x)=\cup_{n=1}^{\infty} \alpha_{n}$ will be the largest element of $\mathcal{A}(T, x)$. The set $\pi(T, x)$ is called the local quasianalytic spectral set of $T$ at $x$. (Note that $\pi(T, x)$ is uniquely determined up to sets of measure 0.) We recall from [Kér11] that $T$ is quasianalytic on $\alpha$ if $\mathcal{H}_{0}(T, F)=\{0\}$ whenever $N_{F} \cap \alpha \neq \emptyset$; the (global) quasianalytic spectral set $\pi(T)$ is the largest element of $\mathcal{A}(T)$, the system of sets where $T$ is quasianalytic. The following statement follows immediately from the definitions.

Proposition 3.1. The set $\pi(T)$ is the largest measurable set such that $\pi(T) \subset$ $\pi(T, x)$ holds for every non-zero $x \in \mathcal{H}$.

The next lemma claims that local stability is determined by the asymptotic density function.

Lemma 3.2. Let $F=\left\{f_{n}\right\}_{n=1}^{\infty}$ be a decreasing sequence in $H^{\infty}$ and $x \in \mathcal{H}$.

(a) If $\lim _{n \rightarrow \infty}\left\|f_{n}(T) x\right\|=0$ then $\varphi_{F} w_{x, x}=0$. 
(b) If $\varphi_{F} w_{x, x}=0$ then there exists an increasing mapping $\tau: \mathbb{N} \rightarrow \mathbb{N}$ such that $\lim _{n \rightarrow \infty}\left\|T^{\tau(n)} f_{n}(T) x\right\|=0$.

Proof. Part (a) readily follows from the equations

$$
\begin{aligned}
\lim _{n \rightarrow \infty}\left\|X f_{n}(T) x\right\|^{2} & =\lim _{n \rightarrow \infty}\left\|f_{n}(V) X x\right\|^{2} \\
& =\lim _{n \rightarrow \infty} \int_{\mathbb{T}}\left|f_{n}\right|^{2} w_{x, x} \mathrm{~d} m=\int_{\mathbb{T}} \varphi_{F}^{2} w_{x, x} \mathrm{~d} m .
\end{aligned}
$$

Since there exists an increasing $\tau: \mathbb{N} \rightarrow \mathbb{N}$ satisfying the condition

$$
\lim _{n \rightarrow \infty}\left\|X f_{n}(T) x\right\|=\lim _{n \rightarrow \infty}\left\|T^{\tau(n)} f_{n}(T) x\right\|,
$$

the same equations yield (b) too.

Note that $G=\left\{\chi^{\tau(n)} f_{n}\right\}_{n=1}^{\infty}$ is also a decreasing sequence with $\varphi_{G}=\varphi_{F}$.

The following theorem establishes connection among the local and global spectral invariants introduced before.

Theorem 3.3. For every non-zero $x \in \mathcal{H}$ we have

$$
\pi(T) \subset \pi(T, x)=\omega(T, x) \subset \omega(T) .
$$

Proof. Let $F=\left\{f_{n}\right\}_{n=1}^{\infty}$ be a decreasing sequence with $N_{F} \cap \omega(T, x) \neq \emptyset$. Then $\varphi_{F} w_{x, x} \neq 0$ implies $\lim _{n \rightarrow \infty}\left\|f_{n}(T) x\right\|>0$ by Lemma 3.2. Thus $T$ is quasianalytic on $\omega(T, x)$ at $x$, and so $\omega(T, x) \subset \pi(T, x)$.

Setting $\alpha=\mathbb{T} \backslash \omega(T, x)$, let $\vartheta \in H^{\infty}$ be such that $|\vartheta|=\chi_{\alpha}+\frac{1}{2} \chi_{\mathbb{T} \backslash \alpha}$, and form the decreasing sequence $F=\left\{\vartheta^{n}\right\}_{n=1}^{\infty}$ with $\varphi_{F}=\chi_{\alpha}$. By Lemma 3.2, $\varphi_{F} w_{x, x}=0$ yields the existence of an increasing $\tau: \mathbb{N} \rightarrow \mathbb{N}$ such that $\lim _{n \rightarrow \infty}\left\|T^{\tau(n)} f_{n}(T) x\right\|=0$. Then $G=\left\{\chi^{\tau(n)} \vartheta^{n}\right\}_{n=1}^{\infty}$ is a decreasing sequence with $N_{G}=\alpha$ and $x \in \mathcal{H}_{0}(T, G)$. Therefore $\pi(T, x) \subset \omega(T, x)$ must hold.

As a consequence we obtain conditions for the existence of a non-trivial hyperinvariant subspace. (Statement (b) below appears already in [Kér01].)

\section{Corollary 3.4.}

(a) If $\omega(T, x) \neq \omega(T)$ for some non-zero $x \in \mathcal{H}$ and $F=\left\{f_{n}\right\}_{n=1}^{\infty}$ is a decreasing sequence with $N_{F}=\omega(T) \backslash \omega(T, x)$, then there exists an increasing mapping $\tau: \mathbb{N} \rightarrow \mathbb{N}$, such that $G=\left\{\chi^{\tau(n)} f_{n}\right\}_{n=1}^{\infty}$ is also a decreasing sequence with $\varphi_{G}=\varphi_{F}, x \in \mathcal{H}_{0}(T, G)$, and $\mathcal{H}_{0}(T, G) \cap \mathcal{H}_{\omega}(T)=\emptyset$. Therefore $\mathcal{H}_{0}(T, G)$ is a non-trivial hyperinvariant subspace of $T$. 
(b) If $\pi(T) \neq \omega(T)$ then Hlat $T$ is non-trivial.

Remark 3.5. We know that $\omega(T, x)=\omega(T)$ for every $x \in \mathcal{H}_{\omega}(T)$, which is a dense $G_{\delta^{-}}$set in $\mathcal{H}$. On the other hand, it may happen that $\pi(T, x) \neq \pi(T)$ for every non-zero $x \in \mathcal{H}$. Indeed, let $\alpha_{1}$ and $\alpha_{2}$ be sets of positive measure on $\mathbb{T}$ such that $\alpha_{1} \neq \alpha \neq \alpha_{2}$ holds for $\alpha=\alpha_{1} \cap \alpha_{2}$. For $j=1,2$, let $T_{j} \in \mathcal{L}\left(\mathcal{H}_{j}\right)$ be an a.c. contraction satisfying the condition $\pi\left(T_{j}\right)=\omega\left(T_{j}\right)=\alpha_{j}$. (Existence of such $T_{j}$ follows from the results in Section 3.2.) Form the orthogonal sum $T=T_{1} \oplus T_{2} \in \mathcal{L}\left(\mathcal{H}=\mathcal{H}_{1} \oplus \mathcal{H}_{2}\right)$. For a non-zero $x=x_{1} \oplus x_{2} \in \mathcal{H}$ the local residual set $\omega(T, x)$ is $\alpha_{1}$ if $x_{2}=0, \alpha_{2}$ if $x_{1}=0$, and $\alpha_{1} \cup \alpha_{2}$ if $x_{1} \neq 0 \neq x_{2}$. On the other hand $\pi(T)=\alpha$.

It is known that the local asymptotic density function, and so the local quasianalytic spectral set as well, can be expressed in terms of the resolvent as a nontangential limit. (See Lemma 2.2 in [ARS07].)

Proposition 3.6. Given any $x \in \mathcal{H}$ we have

$$
\text { nt- } \lim _{z \rightarrow \zeta}\left(1-|z|^{2}\right)\left\|(I-\bar{z} T)^{-1} x\right\|^{2}=w_{x, x}(\zeta) \quad \text { for a.e. } \zeta \in \mathbb{T} .
$$

Proof. For the sake of completeness we sketch the proof, which is based on the representation of the unitary asymptote in the dilation space.

Let $U_{T^{*},+} \in \mathcal{L}\left(\mathcal{K}_{*,+}\right)$ be the minimal isometric dilation of $T^{*}$. Then $U_{*}=\left(U_{T^{*},+}\right)^{*}$ is minimal coisometric extension of $T$. Taking the Wold decomposition $U_{T^{*},+}=$ $S_{n} \oplus R_{*}^{*} \in \mathcal{L}\left(\mathcal{K}_{*,+}=\mathcal{S}_{*} \oplus \mathcal{R}_{*}\right)$, where $S_{n}$ is a unilateral shift of some multiplicity $n$ and $R_{*}$ is unitary, we obtain the decomposition $U_{*}=S_{n}^{*} \oplus R_{*}$. The pair $\left(X_{*}, R_{*}\right)$ is a unitary asymptote of $T$, where $X_{*}=P_{\mathcal{R}_{*}} \mid \mathcal{H}$.

Given $x \in \mathcal{H}$ we have

$$
\begin{aligned}
& \text { nt- } \lim _{z \rightarrow \zeta}\left(1-|z|^{2}\right)\left\|\left(I-\bar{z} R_{*}\right)^{-1} X_{*} x\right\|^{2} \\
& =\text { nt- } \lim _{z \rightarrow \zeta} \int_{\mathbb{T}} \frac{1-|z|^{2}}{|1-\bar{z} s|^{2}} w_{x, x}(s) \mathrm{d} m(s)=w_{x, x}(\zeta) \quad \text { for a.e. } \zeta \in \mathbb{T} .
\end{aligned}
$$

Notice that the Poisson kernel appears in the integral. Using tools from harmonic analysis it can be shown that, for every $y \in \mathcal{S}_{*}$,

$$
\text { nt- } \lim _{z \rightarrow \zeta}\left(1-|z|^{2}\right)\left\|\left(I-\bar{z} S_{n}^{*}\right)^{-1} y\right\|^{2}=0 \quad \text { for a.e. } \zeta \in \mathbb{T} .
$$

Now the statement follows from the decomposition

$$
(I-\bar{z} T)^{-1} x=\left(I-\bar{z} U_{*}\right)^{-1} x=\left(I-\bar{z} S_{n}^{*}\right)^{-1} P_{\mathcal{S}_{*}} x \oplus\left(I-\bar{z} R_{*}\right)^{-1} X_{*} x .
$$




\subsection{Quasianalytic contractions}

The a.c. contraction $T \in \mathcal{L}(\mathcal{H})$ is quasianalytic if $\pi(T)=\omega(T) \neq \emptyset$. In view of Corollary 3.4, in the setting of asymptotically non-vanishing contractions (HSP) can be reduced to the case when $T$ is quasianalytic.

For the sake of convenience and easy reference we collect some fundamental statements on quasianalytic contractions in the following theorem. For their proofs we refer to [Kér01] and [Kér11].

First we recall some definitions. The simple unilateral shift $S \in \mathcal{L}\left(H^{2}\right)$ is defined by $S f=\chi f$. The operator $A \in \mathcal{L}(\mathcal{H})$ is a quasiaffine transform of the operator $B \in \mathcal{L}(\mathcal{K})$, in notation: $A \prec B$, if there exists a quasiaffinity (i.e. an injective transformation with dense range) $Q \in \mathcal{L}(\mathcal{H}, \mathcal{K})$ such that $Q A=B Q$. The operators $A$ and $B$ are quasisimilar, in notation: $A \sim B$, if $A \prec B$ and $B \prec A$. The function $f \in H^{\infty}$ is partially inner if $|f(0)|<1=\|f\|_{\infty}$ and the set $\Omega(f)=\{\zeta \in \mathbb{T}$ : $|f(\zeta)|=1\}$ is of positive measure. The partially inner function $f$ is regular, if $\alpha \subset \Omega(f), m(\alpha)=0$ imply $m(f(\alpha))=0$; or equivalently, if $f(\alpha)$ is measurable whenever $\alpha \subset \Omega(f)$ is measurable.

Theorem 3.7. The operators $T, T_{1}$ and $T_{2}$ below are all a.c. contractions.

(a) The unilateral shift $S \in \mathcal{L}\left(H^{2}\right)$ is quasianalytic with $\pi(S)=\mathbb{T}$.

(b) If $T \prec S$, then $T$ is quasianalytic with $\pi(T)=\mathbb{T}$.

(c) If $T$ is quasianalytic, then its inflation $T^{(n)}=\underbrace{T \oplus \ldots \oplus T}_{n \text { terms }}$ is quasianalytic with $\pi\left(T^{(n)}\right)=\pi(T)(n \in \mathbb{N})$.

(d) If $T$ is quasianalytic and $\mathcal{M}$ is a non-zero invariant subspace of $T$, then $T \mid \mathcal{M}$ is quasianalytic with $\pi(T \mid \mathcal{M})=\pi(T)$.

(e) If $T$ is quasianalytic and $f$ is a regular partially inner function satisfying the condition $\Omega(f) \cap \pi(T) \neq \emptyset$, then $f(T)$ is quasianalytic with $\pi(f(T))=$ $f(\Omega(f) \cap \pi(T))$.

(f) If $T_{1} \sim T_{2}$ and $T_{1}$ is quasianalytic, then $T_{2}$ is also quasianalytic with $\pi\left(T_{2}\right)=$ $\pi\left(T_{1}\right)$.

On the basis of these statements a lot of examples of quasianalytic contractions can be constructed.

We show that quasianalycity determines asymptotic behaviour of the contraction. 
Theorem 3.8. If $T$ is a quasianalytic contraction, then $T \in C_{10}$.

Proof. Since $\pi(T) \neq \emptyset$ and $F=\left\{\chi^{n}\right\}_{n=1}^{\infty}$ is a decreasing sequence with $N_{F}=\mathbb{T}$, we infer that $T \in C_{1}$.

Let us suppose that $T \notin C_{.0}$. Then $\mathcal{H}_{1}=\mathcal{H}_{0}\left(T^{*}\right)^{\perp}$ is a non-zero invariant subspace of $T$ and $T_{1}=T \mid \mathcal{H}_{1} \in C_{11}$. Hence $T_{1}$ is quasisimilar to an a.c. unitary operator $V_{1}$. By (d) and (f) of Theorem 3.7 it follows that $V_{1}$ is quasianalytic, what is impossible since $\pi\left(V_{1}\right)=\emptyset \neq \omega\left(V_{1}\right)$. Therefore $T \in C_{.0}$.

\subsection{Asymptotically cyclic contractions}

Let $T \in \mathcal{L}(\mathcal{H})$ be an a.c. contraction, and let $(X, V)$ be a unitary asymptote of $T$. We say that $T$ is asymptotically cyclic, if the a.c. unitary operator $V \in \mathcal{L}(\mathcal{K})$ is cyclic, that is $\vee_{n=0}^{\infty} V^{n} y=\mathcal{K}$ holds for some $y \in \mathcal{K}$. It is known that $V$ is cyclic exactly when its commutant $\{V\}^{\prime}=\{D \in \mathcal{L}(\mathcal{K}): D V=V D\}$ is abelian. The universal property of the unitary asymptote implies that for every $C \in\{T\}^{\prime}$ there is a unique $D \in\{V\}^{\prime}$ such that $X C=D X$, and the mapping $\gamma:\{T\}^{\prime} \rightarrow\{V\}^{\prime}, C \mapsto D$ is a contractive, unital algebra-homomorphism (see [NFBK, Lemma IX.1.4]). Hence $\{T\}^{\prime}$ is abelian if so is $\{V\}^{\prime}$ and $\gamma$ is injective, which is evidently true if $T \in C_{1}$.. (Injectivity of $\gamma$ was studied in [GK11].)

We give sufficient condition for the contraction $T$ to be asymptotically cyclic. First we fix some notation. Given $A \in \mathcal{L}(\mathcal{E})$ and $B \in \mathcal{L}(\mathcal{F}), \mathcal{I}(A, B)=\{Q \in$ $\mathcal{L}(\mathcal{E}, \mathcal{F}): Q A=B Q\}$ is the set of transformations intertwining $A$ with $B$. The operators $A$ and $B$ are unitarily equivalent, in notation: $A \cong B$, if $\mathcal{I}(A, B)$ contains a unitary transformation. Moreover, $A$ and $B$ are similar, in notation: $A \approx B$, if $\mathcal{I}(A, B)$ contains an affinity (invertible transformation). Finally $A$ can be injected into $B$, in notation: $A \stackrel{i}{\prec} B$, if $\mathcal{I}(A, B)$ contains an injection. The minimal unitary extension of the simple unilateral shift $S \in \mathcal{L}\left(H^{2}\right)$ is the simple bilateral shift $\widetilde{S} \in$ $\mathcal{L}\left(L^{2}(\mathbb{T})\right)$, defined by $\widetilde{S} f=\chi f$.

Proposition 3.9. If $T \in \mathcal{L}(\mathcal{H})$ is a contraction and $T \prec S$, then $T$ is asymptotically cyclic and $V \mid(X \mathcal{H})^{-} \cong S$.

Proof. The relation $T \prec S$ immediately implies that $T \in C_{10}$; in particular, $T$ is a.c. and the unitary asymptote $V$ acts on a non-zero space $\mathcal{K}$. Suppose that $V$ is not cyclic. Then $S_{2}=S \oplus S \stackrel{i}{\prec} T$ by Theorem 1 in [Kér07] (see also Theorem IX.3.2 
in [NFBK]). Thus $S_{2} \stackrel{i}{\prec} S$, what is impossible by Theorem 5 in [NF74]. Therefore $V$ is cyclic, that is $T$ is asymptotically cyclic.

Let $Q \in \mathcal{I}(T, S)$ be a quasiaffinity, and let $\widetilde{Q} \in \mathcal{I}(T, \widetilde{S})$ be defined by $\widetilde{Q} h=Q h$ $(h \in \mathcal{H})$. There exists unique $Y \in \mathcal{I}(V, \widetilde{S})$ such that $\widetilde{Q}=Y X$. It is known that $\operatorname{ker} Y$ is reducing for $V,(Y \mathcal{K})^{-}$is reducing for $\widetilde{S}$, and $V\left|(\operatorname{ker} Y)^{\perp} \cong \widetilde{S}\right|(Y \mathcal{K})^{-}$. Since $(Y \mathcal{K})^{-} \supset(Q \mathcal{H})^{-}=H^{2}$, it follows that $(Y \mathcal{K})^{-}=L^{2}(\mathbb{T})$, and so $V \mid(\operatorname{ker} Y)^{\perp} \cong$ $\widetilde{S}$. Taking into account that $V$ is cyclic, we infer that $\operatorname{ker} Y=\{0\}$, thus $Y$ is a quasiaffinity. The relations $Y(X \mathcal{H})^{-} \subset(Y X \mathcal{H})^{-}=(Q \mathcal{H})^{-}=H^{2}$ imply that $(X \mathcal{H})^{-}$is a non-trivial invariant subspace of $V$. Since $\vee_{n=0}^{\infty} V^{-n}(X \mathcal{H})^{-}=\mathcal{K}$, we conclude that $V \mid(X \mathcal{H})^{-} \cong S$.

We note that $S_{2} \prec \widetilde{S}$, and so $T \prec \widetilde{S}$ does not imply that $T$ is asymptotically cyclic. Indeed, $Q \in \mathcal{I}\left(S_{2}, \widetilde{S}\right)$, defined by $Q(f \oplus g)=\vartheta f+g$, is a quasiaffinity, provided $\vartheta \in L^{\infty}(\mathbb{T})$ is a.e. non-zero and $\int_{\mathbb{T}} \log |\vartheta| \mathrm{d} m=-\infty$.

The set of asymptotically cyclic, quasianalytic contractions acting on the Hilbert space $\mathcal{H}$ is denoted by $\mathcal{L}_{0}(\mathcal{H})$. If $T$ is cyclic then so is $V$ (but not conversely), hence (ISP) in the setting of quasianalytic contractions can be reduced to the class $\mathcal{L}_{0}(\mathcal{H})$.

Proposition 3.10. If $T \in \mathcal{L}_{0}(\mathcal{H})$ then

(i) $\{T\}^{\prime}$ is abelian, and

(ii) every non-zero $C \in\{T\}^{\prime}$ is injective.

Proof. If $T \in \mathcal{L}_{0}(\mathcal{H})$ then $T \in C_{10}$ by Theorem 3.8, and so $\gamma$ is injective. Since $\{V\}^{\prime}$ is abelian it follows that $\{T\}^{\prime}$ is abelian too. For the proof of (ii) see Proposition 23 in [Kér01].

Proposition 3.11. If $T_{1}, T_{2} \in \mathcal{L}_{0}(\mathcal{H})$ and $T_{1} T_{2}=T_{2} T_{1}$, then $\left\{T_{1}\right\}^{\prime}=\left\{T_{2}\right\}^{\prime}$.

Proof. Fix any $C \in\left\{T_{1}\right\}^{\prime}$. Since $T_{2} \in\left\{T_{1}\right\}^{\prime}$, the commutativity of $\left\{T_{1}\right\}^{\prime}$ yields $C T_{2}=T_{2} C$, that is, $C \in\left\{T_{2}\right\}^{\prime}$.

We have a lot of information on the structure of a contraction if its residual set covers the unit circle. Hence it is worth considering the special class $\mathcal{L}_{1}(\mathcal{H})=\{T \in$ $\left.\mathcal{L}_{0}(\mathcal{H}): \pi(T)=\mathbb{T}\right\}$. In the next theorem we summarize important properties of an operator $T \in \mathcal{L}_{1}(\mathcal{H})$; for the proof we refer to Section IX.3 in [NFBK]. We recall that Lat $_{\mathrm{s}} T$ stands for the set of those invariant subspaces $\mathcal{M}$, where the restriction $T \mid \mathcal{M}$ is similar to $S$. The range of the functional calculus $\Phi_{T}$ is denoted by $H^{\infty}(T)$, and 
the algebra $\mathcal{W}(T)$ is the closure of $H^{\infty}(T)$ in the weak operator topology. Finally $T$ is called reflexive if $C \in \mathcal{W}(T)$ whenever Lat $C \supset$ Lat $T$.

Theorem 3.12. If $T \in \mathcal{L}_{1}(\mathcal{H})$ then

(i) $\vee \operatorname{Lat}_{\mathrm{s}} T=\mathcal{H}$,

(ii) $\Phi_{T}$ is an isometry,

(iii) $H^{\infty}(T)=\mathcal{W}(T)$, and

(iv) $T$ is reflexive.

Examples of operators in $\mathcal{L}_{1}(\mathcal{H})$ are provided by the following propositions.

Proposition 3.13. If $T \in \mathcal{L}(\mathcal{H})$ is a contraction such that $T \prec S$, then $T \in \mathcal{L}_{1}(\mathcal{H})$ and $H^{\infty}(T)=\{T\}^{\prime}$.

Proof. By Theorem 3.7.(b) and Proposition 3.9 it follows that $T \in \mathcal{L}_{1}(\mathcal{H})$. For the proof of $H^{\infty}(T)=\{T\}^{\prime}$ see Proposition 5.3 in [Kér11].

Proposition 3.14. If $T \in \mathcal{L}_{1}(\mathcal{H})$, then $T \mid \mathcal{M} \in \mathcal{L}_{1}(\mathcal{M})$ holds for every non-zero invariant subspace $\mathcal{M}$ of $T$.

Proof. The restriction $T \mid \mathcal{M}$ is quasianalytic with $\pi(T \mid \mathcal{M})=\pi(T)=\mathbb{T}$ by Theorem 3.7.(d). Since $T$ is asymptotically cyclic, so is $T \mid \mathcal{M}$, since its unitary asymptote is a direct summand of $V$.

There is a strong connection between the classes $\mathcal{L}_{0}(\mathcal{H})$ and $\mathcal{L}_{1}(\mathcal{H})$. The following statement appears in [KT12] as Theorem 1.

Theorem 3.15. For every $T_{0} \in \mathcal{L}_{0}(\mathcal{H})$ we can find $T_{1} \in \mathcal{L}_{1}(\mathcal{H})$ so that $T_{0} T_{1}=T_{1} T_{0}$; hence $\left\{T_{0}\right\}^{\prime}=\left\{T_{1}\right\}^{\prime}$ and so Hlat $T_{0}=$ Hlat $T_{1}$.

Therefore, $(\mathrm{HSP})$ in $\mathcal{L}_{0}(\mathcal{H})$ can be reduced to $\mathcal{L}_{1}(\mathcal{H})$, where Theorem 3.12 provides a lot of information on the operator. If $\{T\}^{\prime}=H^{\infty}(T)$, then Hlat $T=\operatorname{Lat} T$ is non-trivial. However, if $\{T\}^{\prime} \neq H^{\infty}(T)$ then the shift-type invariant subspaces are not hyperinvariant.

Proposition 3.16. Let $T \in \mathcal{L}_{1}(\mathcal{H})$ be such that $\{T\}^{\prime} \neq H^{\infty}(T)$. Then, for every $C \in\{T\}^{\prime} \backslash H^{\infty}(T)$, we have Lat $C \cap \operatorname{Lat}_{\mathrm{s}} T=\emptyset$. 
Proof. Let $C \in\{T\}^{\prime}$ be such that $C \mathcal{M} \subset \mathcal{M}$ holds for some $\mathcal{M} \in \operatorname{Lat}_{\mathrm{s}} T$. Since $\{T \mid \mathcal{M}\}^{\prime}=H^{\infty}(T \mid \mathcal{M})$ by Proposition 3.13 and $C \mid \mathcal{M} \in\{T \mid \mathcal{M}\}^{\prime}$, there exists $f \in H^{\infty}$ such that $C|\mathcal{M}=f(T \mid \mathcal{M})=f(T)| \mathcal{M}$. In view of Proposition 3.10.(ii), the relations $C-f(T) \in\{T\}^{\prime}$ and $(C-f(T)) \mid \mathcal{M}=0$ yield that $C=f(T)$.

Corollary 3.17. For any $T \in \mathcal{L}_{1}(\mathcal{H}),\{T\}^{\prime}=H^{\infty}(T)$ holds if and only if Hlat $T=$ Lat $T$.

The following theorem states that if non-trivial hyperinvariant subspaces exist, then such subspaces can be derived from shift-type invariant subspaces.

Theorem 3.18. Let $T \in \mathcal{L}_{1}(\mathcal{H})$ be such that $\{T\}^{\prime} \neq H^{\infty}(T)$. Then the following statements are equivalent:

(i) Hlat $T$ is non-trivial;

(ii) there exists $\mathcal{M} \in \operatorname{Lat}_{\mathrm{s}} T$ such that $\vee\left\{C \mathcal{M}: C \in\{T\}^{\prime}\right\} \neq \mathcal{H}$;

(iii) there exists $\mathcal{S} \subset$ Lat $_{\mathrm{s}} T$ such that $\mathcal{H} \neq \vee \mathcal{S} \in$ Hlat $T$.

Proof. Let us assume that $\mathcal{N}$ is a non-trivial hyperinvariant subspace of $T$. Since $T \mid \mathcal{N} \in \mathcal{L}_{1}(\mathcal{N})$, there exists a subspace $\mathcal{M} \in \operatorname{Lat}_{\mathrm{s}}(T \mid \mathcal{N}) \subset \operatorname{Lat}_{\mathrm{s}} T$ included in $\mathcal{N}$ (see Theorem 3.12 and Proposition 3.14). It is clear that $\mathcal{N}_{0}=\vee\left\{C \mathcal{M}: C \in\{T\}^{\prime}\right\}$ is a hyperinvariant subspace satisfying the conditions $\mathcal{M} \subset \mathcal{N}_{0} \subset \mathcal{N}$, in particular $\mathcal{N}_{0}$ is non-trivial.

For any $C \in\{T\}^{\prime}$ and $\lambda \in \mathbb{C}$, we have $(C-\lambda I) \mathcal{M} \vee \mathcal{M}=C \mathcal{M} \vee \mathcal{M}$. Hence $\mathcal{N}_{0}=\vee\left\{C \mathcal{M}: C \in\{T\}^{\prime}\right.$ invertible $\}$. However, if $C \in\{T\}^{\prime}$ is invertible, then $T|C \mathcal{M} \approx T| \mathcal{M} \approx S$ and so $C \mathcal{M} \in \operatorname{Lat}_{\mathrm{s}}(T)$.

It is known that the unilateral shift $S$ is cellular-indecomposable, that is the intersection of any two non-zero invariant subspaces of $S$ is non-zero. The contraction $T \in \mathcal{L}_{1}(\mathcal{H})$ is called quasiunitary, if $X$ has dense range and so it is a quasiaffinity, where $(X, V)$ is a unitary asymptote of $T$. (See Section 5 in [Kér01].)

Proposition 3.19. If $T \in \mathcal{L}_{1}(\mathcal{H})$, then the following conditions are equivalent:

(i) $T$ is not quasiunitary,

(ii) $T \prec S$,

(iii) $T$ is cellular-indecomposable. 
Proof. Let $(X, V)$ be a unitary asymptote of $T$; we know that $\mathcal{L}(\mathcal{K}) \ni V \cong \widetilde{S}$. The subspace $(X \mathcal{H})^{-}$is invariant for $V$ and $\vee_{n=1}^{\infty} V^{-n}(X \mathcal{H})^{-}=\mathcal{K}$. Hence, if $(X \mathcal{H})^{-} \neq \mathcal{K}$ then $V \mid(X \mathcal{H})^{-} \cong S$, and so (i) implies (ii). The converse implication follows from Proposition 3.9, thus (i) and (ii) are equivalent.

If $T$ is not quasiunitary, then the relation $S \prec \widetilde{S}$ implies $T \prec \widetilde{S}$. Hence $T \prec \widetilde{S}$ always holds. Therefore, (ii) and (iii) are equivalent by the result of [Tak90].

If $T$ is not quasiunitary, then Hlat $T=$ Lat $T$ is a rich lattice containing $\operatorname{Lat}_{\mathrm{s}} T$ and $\left(\operatorname{ker}\left(T^{*}-\bar{\lambda} I\right)\right)^{\perp}(\lambda \in \mathbb{D})$ because of $S^{*} \prec T^{*}$. (See Propositions 3.13, 3.19 and Theorem 3.12.) Hence (HSP) in $\mathcal{L}_{1}(\mathcal{H})$ can be reduced to the quasiunitary case. Propositions 3.14, 3.19 and Theorem 3.12 yield:

Proposition 3.20. If $T \in \mathcal{L}_{1}(\mathcal{H})$ is quasiunitary, then there exist $\mathcal{M}_{1}, \mathcal{M}_{2} \in \operatorname{Lat}_{\mathrm{s}} T$ such that $\mathcal{M}_{1} \cap \mathcal{M}_{2}=\{0\}$.

\subsection{Functional commutant}

Let $T \in \mathcal{L}(\mathcal{H})$ be an asymptotically cyclic a.c. contraction, and assume that $T \in$ $C_{1}$. and $\omega(T)=\mathbb{T}$. Let $(X, V)$ be a unitary asymptote of $T$, and let us consider the contractive algebra-homomorphism $\gamma:\{T\}^{\prime} \rightarrow\{V\}^{\prime}, C \mapsto D$, where $X C=$ $D X$, which is injective because of $T \in C_{1}$.. The functional calculus $\Phi: L^{\infty}(\mathbb{T}) \rightarrow$ $\{V\}^{\prime}, f \mapsto f(V)$ is an isomorphism between the corresponding Banach algebras. The composition $\widehat{\gamma}_{T}=\Phi^{-1} \circ \gamma:\{T\}^{\prime} \rightarrow L^{\infty}(\mathbb{T})$ is also an injective, contractive, unital algebra-homomorphism. It can be easily checked that $\widehat{\gamma}_{T}$ is independent of the special choice of $(X, V)$. Indeed, for $j=1,2$ let $\left(X_{j}, V_{j}\right)$ be a unitary asymptote of $T$, and let $\gamma_{j}, \Phi_{j}$ be defined as before. There exist unitary transformations $Y_{1} \in$ $\mathcal{I}\left(V_{1}, V_{2}\right)$ and $Y_{2} \in \mathcal{I}\left(V_{2}, V_{1}\right)$ such that $X_{2}=Y_{1} X_{1}, X_{1}=Y_{2} X_{2}$ and $Y_{2}=Y_{1}^{-1}$. Given any $C \in\{T\}^{\prime}$ we have $X_{j} C=D_{j} X_{j}=f_{j}\left(V_{j}\right) X_{j}$. Hence

$$
f_{2}\left(V_{1}\right) X_{1}=Y_{2} f_{2}\left(V_{2}\right) Y_{1} X_{1}=Y_{2} f_{2}\left(V_{2}\right) X_{2}=Y_{2} X_{2} C=X_{1} C=f_{1}\left(V_{1}\right) X_{1},
$$

and so $f_{2}\left(V_{1}\right)=f_{1}\left(V_{1}\right)$, whence $f_{2}=f_{1}$ follows.

The uniquely determined $\widehat{\gamma}_{T}$ is called the functional mapping of $T$, and its range $\mathcal{F}(T)$ is called the functional commutant of $T$. Since $\widehat{\gamma}_{T}(f(T))=f$ holds for every $f \in H^{\infty}$, we obtain that $\mathcal{F}(T)$ is a subalgebra of $L^{\infty}(\mathbb{T})$ containing $H^{\infty}$. It is natural to ask the following questions. Which function algebras $H^{\infty} \subset \mathcal{A} \subset L^{\infty}(\mathbb{T})$ are attainable as a functional commutant: $\mathcal{A}=\mathcal{F}(T)$, and what kind of information 
can be derived from the properties of $\widehat{\gamma}_{T}$ and $\mathcal{F}(T)$ on the behaviour of $T$ ? We recall that the function algebra $\mathcal{A}$ is called quasianalytic, if $f(\zeta) \neq 0$ for a.e. $\zeta \in \mathbb{T}$ whenever $f$ is a non-zero element of $\mathcal{A}$. The following statement was proved in [Kér11] (see Proposition 4.2 there).

Proposition 3.21. If $T \in \mathcal{L}_{1}(\mathcal{H})$, then $\mathcal{F}(T)$ is quasianalytic.

It is clear that $\mathcal{F}(T)=H^{\infty}$ exactly when $\{T\}^{\prime}=H^{\infty}(T)$, and this happens in particular if $T \prec S$. (For a more complete characterization of this case see Theorem 5.2 in [Kér11].)

If $T \in \mathcal{L}_{1}(\mathcal{H})$ and $\mathcal{F}(T) \neq H^{\infty}$, then the closure $\mathcal{F}(T)^{-}$contains $H^{\infty}+C(\mathbb{T})$ (see Theorems IX.1.4 and IX.2.2 in [Gar07]); thus $\mathcal{F}(T)^{-}$is not quasianalytic, and so $\mathcal{F}(T)$ is not closed, or equivalently, $\widehat{\gamma}_{T}$ is not bounded from below.

We recall that $\eta \in H^{\infty}$ is an inner function, if $|\eta(\zeta)|=1$ holds for a.e. $\zeta \in \mathbb{T}$. Let $H_{\mathrm{i}}^{\infty}$ stand for the multiplicative semigroup of all inner functions. Given a subsemigroup $\mathcal{B}$ of $H_{\mathrm{i}}^{\infty}$, the algebra $\overline{\mathcal{B}} \cdot H^{\infty}$ generated by $\overline{\mathcal{B}}$ (set of conjugates of functions in $\mathcal{B})$ and $H^{\infty}$ is clearly quasianalytic. The closure $\left(\overline{\mathcal{B}} \cdot H^{\infty}\right)^{-}$is called the Douglas algebra induced by $\mathcal{B}$. By the celebrated Chang-Marshall theorem every closed subalgebra $\mathcal{A}$ of $L^{\infty}(\mathbb{T})$, containing $H^{\infty}$, is a Douglas algebra (see Theorem IX.3.1 in [Gar07]). Therefore, $\mathcal{F}(T)^{-}=\left(\overline{\mathcal{B}} \cdot H^{\infty}\right)^{-}$holds with $\mathcal{B}=\left\{\eta \in \mathcal{F}(T)^{-} \cap\right.$ $\left.H_{\mathrm{i}}^{\infty}: \bar{\eta} \in \mathcal{F}(T)^{-}\right\}$. We note that $\mathcal{B}$ can be replaced by a semigroup generated by interpolating Blaschke products (see Theorems IX.3.2 and IX.3.4 in [Gar07]). The question which pre-Douglas algebras $\overline{\mathcal{B}} \cdot H^{\infty}$ arise as functional commutants of contractions of class $\mathcal{L}_{1}(\mathcal{H})$ was posed in [Kér11]. The next theorem settles this problem.

Theorem 3.22. The only attainable pre-Douglas algebra is $H^{\infty}$.

Proof. Set $T \in \mathcal{L}_{1}(\mathcal{H})$, and let us assume that $\mathcal{F}(T) \neq H^{\infty}$. If the spectrum $\sigma(T)$ of $T$ covers the closed unit disc $\mathbb{D}^{-}$, then $\bar{\eta} \notin \mathcal{F}(T)$ for every non-constant $\eta \in H_{\mathrm{i}}^{\infty}$ (see Proposition 4.4 in [Kér11]), hence $\mathcal{F}(T)$ can't be a pre-Douglas algebra. Let us assume now that $\sigma(T) \neq \mathbb{D}^{-}$. Select a point $a \in \mathbb{D} \backslash \sigma(T)$, and consider the operator $A=(T-a I)^{-1} \in\{T\}^{\prime}$ and the function $g=\widehat{\gamma}_{T}(A)=(\chi-a)^{-1} \in \mathcal{F}(T)$. Since $\widetilde{A}:=\exp A=\sum_{n=0}^{\infty}(n !)^{-1} A^{n} \in\{T\}^{\prime}$, it follows that $\widetilde{g}:=\widehat{\gamma}_{T}(\widetilde{A})=\sum_{n=0}^{\infty}(n !)^{-1} g^{n}=$ $\exp g$ belongs to $\mathcal{F}(T)$. The function $\widetilde{g}$, defined on $\mathbb{T}$, has an analytic extension $G(z)=\exp (1 /(z-a))$ defined for $z \in \mathbb{C} \backslash\{a\}$. It is clear that $a$ is an essential isolated singularity of $G$. Let us assume that we can find functions $h \in H^{\infty}$ and 
$k \in H_{\mathrm{i}}^{\infty}$ so that $\widetilde{g}=h \bar{k}=h / k$. Let $H$ and $K$ be analytic extensions of $h$ and $k$, respectively, onto $\mathbb{D}$. Then $H / K$ is a meromorphic function on $\mathbb{D}$, and

$$
\mathrm{nt}-\lim _{z \rightarrow \zeta} \frac{H(z)}{K(z)}=\frac{h(\zeta)}{k(\zeta)}=\widetilde{g}(\zeta)=G(\zeta)
$$

holds for every $\zeta \in \omega_{0}$, where $m\left(\mathbb{T} \backslash \omega_{0}\right)=0$. Let $\Omega$ be a domain in $\mathbb{D}$ bounded by an open arc $\alpha_{1}$ on $\mathbb{T}$ and a closed segment $\alpha_{2}$, such that $a \notin \Omega^{-}$. Let $\psi$ be a conformal mapping of $\mathbb{D}$ onto $\Omega$, and let us consider the bounded analytic function $F=(H \circ \psi)-(G \circ \psi)(K \circ \psi)$ on $\mathbb{D}$. By Carathéodory's theorem $\psi$ can be extended to a homeomorphism of $\mathbb{D}^{-}$onto $\Omega^{-}$. Since the Jordan curve $\partial \Omega$ is rectifiable, the set $\omega_{1}=\psi^{-1}\left(\omega_{0} \cap \alpha_{1}\right) \subset \mathbb{T}$ is of positive measure. For every $\zeta \in \omega_{1}$, an $r_{\zeta} \in(0,1)$ can be given so that $I_{\zeta}=\left\{r \psi(\zeta): r_{\zeta} \leq r<1\right\} \subset \Omega$. Then the $\operatorname{arc} C_{\zeta}=\psi^{-1}\left(I_{\zeta}\right) \subset \mathbb{D}$ terminates in $\zeta$, and $F(z)$ converges to 0 when $z$ tends to $\zeta$ along $C_{\zeta}$. We conclude that nt- $\lim _{z \rightarrow \zeta} F(z)=0$ by Lindelöf's theorem (see Theorem 2.3 in [CL66]). Hence the theorem of F. and M. Riesz implies that $F$ is identically zero (see Theorem 2.5 in [CL66]). Therefore, we obtain that $G=H / K$, what is impossible since $H / K$ is meromorphic on $\mathbb{D}$ and $a \in \mathbb{D}$ is an essential singularity.

Special case of the following property of the functional commutant has been exploited in the previous proof.

Proposition 3.23. If $f \in \mathcal{F}(T), r>\left\|\widehat{\gamma}_{T}^{-1}(f)\right\|$ and $\varphi$ is analytic on $r \mathbb{D}$, then $\varphi \circ f \in \mathcal{F}(T)$.

Proof. Consider the Taylor expansion $\varphi(z)=\sum_{n=0}^{\infty} c_{n} z^{n}(z \in r \mathbb{D})$, where, of course, $\varlimsup_{n \rightarrow \infty} \sqrt[n]{\left|c_{n}\right|} \leq 1 / r$. Setting $C=\widehat{\gamma}_{T}^{-1}(f) \in\{T\}^{\prime}$, we know that $\widetilde{C}=\varphi(C)=$ $\sum_{n=0}^{\infty} c_{n} C^{n} \in\{T\}^{\prime}$ (convergence in norm), and so

$$
\varphi(f)=\sum_{n=0}^{\infty} c_{n} f^{n}=\widehat{\gamma}_{T}(\widetilde{C}) \in \mathcal{F}(T) .
$$

We recall that $H^{\infty} \subset \mathcal{A} \subset L^{\infty}$ is a generalized Douglas algebra, if for every $f \in \mathcal{A}$ and $\lambda \in \mathbb{C},|\lambda|>\|f\|_{\infty}$ implies $(f-\lambda)^{-1} \in \mathcal{A}$. These algebras were introduced and studied in [Tol92], where among others Gelfand's theory of maximal ideals and the theory of Douglas algebras were carried over to such algebras. We know that $\mathcal{F}(T)$ is a generalized Douglas algebra if and only if $\widehat{\gamma}_{T}$ preserves the spectral radius, and in that case $\sigma(T)=\mathbb{T}$ (see Theorems 5.5 and 5.6 in [Kér11]). 
It remains open which generalized Douglas algebras, other than $H^{\infty}$, (if there are any) arise as a functional commutant $\mathcal{F}(T)$ of a contraction $T \in \mathcal{L}_{1}(\mathcal{H})$. Are there any quasianalytic generalized Douglas algebras, other than $H^{\infty}$, at all?

We provide an example of an operator $T \in \mathcal{L}_{1}(\mathcal{H})$ such that $\mathcal{F}(T) \neq H^{\infty}$ and $\mathcal{F}(T) \cap \overline{H_{\mathrm{i}}^{\infty}}=\mathbb{T} \mathbb{1}$. (Here $\mathbb{1}$ denotes the constant 1 function.)

Example 3.24. We consider extended version of Example 5.8 in [Kér11]. Given $0 \leq \delta<1$, set $G_{\delta}=\left\{r e^{i t}: \sqrt{\delta}<r<1,0<t<\pi\right\}$. Let $\eta_{\delta}$ denote the conformal mapping of $\mathbb{D}$ onto the domain $G_{\delta}$, satisfying the condition $\eta_{\delta}(\zeta)=\zeta$ for $\zeta=1, i,-1$. Forming the regular partially inner function $\vartheta_{\delta}=\eta_{\delta}^{2}$, let us consider the analytic Toeplitz operator $T_{\delta} \in \mathcal{L}\left(H^{2}\right)$ defined by $T_{\delta} f=\vartheta_{\delta} f$. It can be easily verified (see [Kér11]) that $T_{\delta} \in \mathcal{L}_{1}\left(H^{2}\right), \sigma\left(T_{\delta}\right)=\{z \in \mathbb{C}: \delta \leq|z| \leq 1\}$ and

$$
\mathcal{F}\left(T_{\delta}\right)=\left\{g \in L^{\infty}(\mathbb{T}): g \circ \vartheta_{\delta,+}=h \mid \mathbb{T}_{+} \text {for some } h \in H^{\infty}\right\}
$$

where $\mathbb{T}_{+}=\{z \in \mathbb{C}:|z|=1, \operatorname{Im} z>0\}$ and $\vartheta_{\delta,+}=\vartheta_{\delta} \mid \mathbb{T}_{+}$.

Let $g_{\delta} \in L^{\infty}(\mathbb{T})$ be the inverse of $\vartheta_{\delta,+}$, that is $g_{\delta}\left(\vartheta_{\delta,+}(\zeta)\right)=\zeta$ for every $\zeta \in \mathbb{T}_{+}$. Since $g_{\delta}(\mathbb{T} \backslash\{1\})=\mathbb{T}_{+}$, it follows that $g_{\delta} \notin H^{\infty}$. (Indeed, assuming $g_{\delta} \in H^{\infty}$ let us choose a fractional linear function $\psi$ transforming $\mathbb{T}_{+}$onto $(0,1)$. Then $\operatorname{Im}\left(\psi \circ g_{\delta}\right)=0$ a.e. on $\mathbb{T}$; taking the Poisson transform we obtain that $\operatorname{Im}\left(\psi \circ g_{\delta}\right)$ is zero on $\mathbb{D}$. The Cauchy-Riemann equations yield that $\psi \circ g_{\delta}$ is constant. Thus $g_{\delta}$ is constant, what is impossible because of $g_{\delta}(\mathbb{T} \backslash\{1\})=\mathbb{T}_{+}$.) On the other hand, the equation $g_{\delta} \circ \vartheta_{\delta,+}=\chi \mid \mathbb{T}_{+}$implies that $g_{\delta} \in \mathcal{F}\left(T_{\delta}\right)$. Therefore $\mathcal{F}\left(T_{\delta}\right) \neq H^{\infty}$ for every $\delta \in[0,1)$. In particular, if $\delta=0$ then $\sigma\left(T_{0}\right)=\mathbb{D}^{-}$, whence, by Proposition 4.4.(b) in [Kér11], $\mathcal{F}\left(T_{0}\right) \cap \overline{H_{\mathrm{i}}^{\infty}}=\mathbb{T} \mathbb{1}$ follows.

Though $\mathcal{F}\left(T_{\delta}\right) \neq H^{\infty}$, there is a connection between these algebras. Namely, for any $\delta \in[0,1)$, the commuting relation $T_{\delta} S=S T_{\delta}$ yields that $\left\{T_{\delta}\right\}^{\prime}=\{S\}^{\prime}$ (see Proposition 3.11). It is known that $\{S\}^{\prime}=H^{\infty}(S)$ and $\widehat{\gamma}_{S}$ is an isometry. Thus the composition $\widehat{\gamma}_{T} \circ \widehat{\gamma}_{S}^{-1}$ is a contractive algebra-isomorphism from $H^{\infty}$ onto $\mathcal{F}(T)$.

We show that the functional commutant is a similarity invariant. Actually, the following theorem contains a more general statement.

Theorem 3.25. For $j=1,2$, let $T_{j} \in \mathcal{L}_{1}\left(\mathcal{H}_{j}\right)$ be given with unitary asymptote $\left(X_{j}, V_{j}\right)$. Let us assume that there exist $Y \in \mathcal{I}\left(T_{1}, T_{2}\right)$ and $Z \in \mathcal{I}\left(T_{2}, T_{1}\right)$ such that $Z Y \neq 0$. Then

(a) $Y$ and $Z$ are injective; 
(b) $0 \neq \widehat{\gamma}_{T_{1}}(Z Y)=\widehat{\gamma}_{T_{2}}(Y Z)=$ : g belongs to $\mathcal{F}\left(T_{1}\right) \cap \mathcal{F}\left(T_{2}\right)$ and $g \mathcal{F}\left(T_{1}\right) \subset \mathcal{F}\left(T_{2}\right)$, $g \mathcal{F}\left(T_{2}\right) \subset \mathcal{F}\left(T_{1}\right) ;$

(c) in particular, if $Z Y=I$, that is when $T_{1} \approx T_{2}$, then $g=\mathbb{1}$ and $\mathcal{F}\left(T_{1}\right)=\mathcal{F}\left(T_{2}\right)$.

Proof. By the universality property of the unitary asymptotes there exist $A \in$ $\mathcal{I}\left(V_{1}, V_{2}\right)$ and $B \in \mathcal{I}\left(V_{2}, V_{1}\right)$ such that $A X_{1}=X_{2} Y$ and $B X_{2}=X_{1} Z$. Since $X_{1}(Z Y)=B X_{2} Y=(B A) X_{1}, Z Y \in\left\{T_{1}\right\}^{\prime}$ and $B A \in\left\{V_{1}\right\}^{\prime}$, we infer that $\widehat{\gamma}_{T_{1}}(Z Y)=$ $g$ where $g\left(V_{1}\right)=B A$. Similarly, $A B=h\left(V_{2}\right)$ with $h=\widehat{\gamma}_{T_{2}}(Y Z)$. The assumption $Z Y \neq 0$ yields that $0 \neq g \in \mathcal{F}\left(T_{1}\right)$. Since the function algebra $\mathcal{F}\left(T_{1}\right)$ is quasianalytic, we obtain that $g\left(V_{1}\right)$ is a quasiaffinity, and so $B$ has dense range. Now the equations $g\left(V_{1}\right) B=B A B=B h\left(V_{2}\right)=h\left(V_{1}\right) B$ imply that $g\left(V_{1}\right)=h\left(V_{1}\right)$, whence $g=h$ follows. Thus $Y Z \in\left\{T_{2}\right\}^{\prime}$ is also non-zero, and we conclude by Proposition 3.10.(ii) that $Z Y$ and $Y Z$ are injective, hence $Y$ and $Z$ are injective too.

Given an arbitrary $f_{1} \in \mathcal{F}\left(T_{1}\right)$, let us consider $C_{1}=\left(\widehat{\gamma}_{T_{1}}\right)^{-1}\left(f_{1}\right) \in\left\{T_{1}\right\}^{\prime}, C_{2}=$ $Y C_{1} Z \in\left\{T_{2}\right\}^{\prime}$ and $\widehat{\gamma}_{T_{2}}\left(C_{2}\right)=f_{2}$. Then the equalities

$$
\begin{aligned}
f_{2}\left(V_{2}\right) X_{2} & =X_{2} C_{2}=X_{2} Y C_{1} Z=A X_{1} C_{1} Z=A f_{1}\left(V_{1}\right) X_{1} Z \\
& =A f_{1}\left(V_{1}\right) B X_{2}=f_{1}\left(V_{2}\right) A B X_{2}=f_{1}\left(V_{2}\right) g\left(V_{2}\right) X_{2}
\end{aligned}
$$

yield that $f_{2}=f_{1} g$. Therefore $g \mathcal{F}\left(T_{1}\right) \subset \mathcal{F}\left(T_{2}\right)$, and in a similar way we obtain that $g \mathcal{F}\left(T_{2}\right) \subset \mathcal{F}\left(T_{1}\right)$.

Since $Z$ is injective, the equation $Z Y=I$ is equivalent to the invertibility of $Z$ with $Y=Z^{-1}$. In that case $g=\widehat{\gamma}_{T_{1}}(Z Y)=\mathbb{1}$, and so $\mathcal{F}\left(T_{1}\right)=\mathcal{F}\left(T_{2}\right)$.

We conclude this section by providing representation of the functional mapping in the functional model.

Let $\mathcal{E}, \mathcal{E}_{*}$ be Hilbert spaces, and let $\Theta: \mathbb{D} \rightarrow \mathcal{L}\left(\mathcal{E}, \mathcal{E}_{*}\right)$ be a purely contractive, analytic, inner and $*$-outer function. Then $\mathcal{H}(\Theta)=H^{2}\left(\mathcal{E}_{*}\right) \ominus \Theta H^{2}(\mathcal{E})$ is the corresponding model space, and the model operator $S(\Theta) \in \mathcal{L}(\mathcal{H}(\Theta))$ is defined by $S(\Theta) u=P_{\mathcal{H}(\Theta)}(\chi u)$, where $P_{\mathcal{H}(\Theta)} \in \mathcal{L}\left(H^{2}\left(\mathcal{E}_{*}\right)\right)$ denotes the orthogonal projection onto $\mathcal{H}(\Theta)$. We know that $S(\Theta) \in C_{10}$, and every contraction of class $C_{10}$ is unitarily equivalent to a model operator of this kind. Let us consider the measurable, projection-valued function $\Delta_{*}(\zeta)=I-\Theta(\zeta) \Theta(\zeta)^{*}$ defined for a.e. $\zeta \in \mathbb{T}$, the subspace $\mathcal{R}_{*}=\Delta_{*} L^{2}\left(\mathcal{E}_{*}\right)$ in $L^{2}\left(\mathcal{E}_{*}\right)$, and the a.c. unitary operator $R_{*} \in \mathcal{L}\left(\mathcal{R}_{*}\right)$ defined by $R_{*} v=\chi v$. The pair $\left(X_{*}, R_{*}\right)$ is a unitary asymptote of $S(\Theta)$, where $X_{*} \in \mathcal{L}\left(\mathcal{H}(\Theta), \mathcal{R}_{*}\right)$ is defined by $X_{*} u=\Delta_{*} u$. (For the characteristic properties of $\Delta_{*}$ see $[\operatorname{Kér13].)}$ 
The spectral-multiplicity function of $R_{*}$ is $\delta_{*}(\zeta)=\operatorname{rank} \Delta_{*}(\zeta)$. Hence $S(\Theta)$ is asymptotically cyclic exactly when $\delta_{*} \leq 1$. The asymptotic density function of $S(\Theta)$ at $u, v \in \mathcal{H}(\Theta)$ is $w_{u, v}(\zeta)=\left\langle\Delta_{*}(\zeta) u(\zeta), v(\zeta)\right\rangle$. Thus the local residual set of $S(\Theta)$ at $u$ is $\omega(S(\Theta), u)=\left\{\zeta \in \mathbb{T}: \Delta_{*}(\zeta) u(\zeta) \neq 0\right\}$, while the global residual set is $\omega(S(\Theta))=\left\{\zeta \in \mathbb{T}: \Delta_{*}(\zeta) \neq 0\right\}$. In view of Proposition 3.1 and Theorem 3.3 we obtain the following characterization.

Proposition 3.26. We have $S(\Theta) \in \mathcal{L}_{1}(\mathcal{H}(\Theta))$ if and only if

(i) $\delta_{*}(\zeta)=1$ for a.e. $\zeta \in \mathbb{T}$, and

(ii) $\Delta_{*}(\zeta) u(\zeta) \neq 0$ for a.e. $\zeta \in \mathbb{T}$, whenever $0 \neq u \in \mathcal{H}(\Theta)$.

By the Lifting Theorem $C \in\{S(\Theta)\}^{\prime}$ if and only if there exists a bounded, analytic function $\Psi: \mathbb{D} \rightarrow \mathcal{L}\left(\mathcal{E}_{*}\right)$ such that $\Psi \Theta H^{2}(\mathcal{E}) \subset \Theta H^{2}(\mathcal{E})$ and $C u=P_{\mathcal{H}(\Theta)} \Psi u$ for every $u \in \mathcal{H}(\Theta)$. We note that $\Psi$ can be chosen so that $\|\Psi\|_{\infty}=\|C\|$. Furthermore, the condition $\Psi \Theta H^{2}(\mathcal{E}) \subset \Theta H^{2}(\mathcal{E})$ is equivalent to the existence of a bounded, analytic function $\Psi_{0}: \mathbb{D} \rightarrow \mathcal{L}(\mathcal{E})$ such that $\Psi \Theta=\Theta \Psi_{0}$. Let $H^{\infty}(\Theta)$ stand for the set of all bounded, analytic functions $\Psi: \mathbb{D} \rightarrow \mathcal{L}\left(\mathcal{E}_{*}\right)$ satisfying the condition $\Psi \Theta H^{2}(\mathcal{E}) \subset \Theta H^{2}(\mathcal{E})$, and for any $\Psi \in H^{\infty}(\Theta)$ let $C_{\Psi}$ be the corresponding operator in $\{S(\Theta)\}^{\prime}$ defined by $C_{\Psi} u=P_{\mathcal{H}(\Theta)} \Psi u(u \in \mathcal{H}(\Theta))$. Moreover, let $\Gamma_{\Theta}(\Psi)$ denote the function $\psi \in L^{\infty}(\mathbb{T})$ defined by $\Delta_{*} \Psi \Delta_{*}=\psi \Delta_{*}$. (Notice that $\operatorname{dim} \Delta_{*}(\zeta) \mathcal{E}_{*}=1$ for a.e. $\zeta \in \mathbb{T}$.)

Theorem 3.27. If $S(\Theta) \in \mathcal{L}_{1}(\mathcal{H}(\Theta))$, then for every $\Psi \in H^{\infty}(\Theta)$ we have:

(i) $\Delta_{*} \Psi\left(I-\Delta_{*}\right)=0$, and

(ii) $\widehat{\gamma}_{S(\Theta)}\left(C_{\Psi}\right)=\Gamma_{\Theta}(\Psi)$.

Proof. Set $\Psi \in H^{\infty}(\Theta)$, and let $\psi=\Gamma_{\Theta}(\Psi)$. For any $u \in H^{2}(\mathcal{E})$ and $n \in \mathbb{N}$, we have $\Delta_{*} \Psi \Theta\left(\chi^{-n} u\right)=\chi^{-n} \Delta_{*} \Psi \Theta u=0$, since $\Psi \Theta u \in \Theta H^{2}(\mathcal{E})$ and $\Delta_{*} \Theta=0$. Thus $\Delta_{*} \Psi \Theta v=0$ holds for every $v \in L^{2}(\mathcal{E})$, and so $\Delta_{*} \Psi \Theta=0$. Since $\Theta(\zeta)$ is an isometry from $\mathcal{E}$ onto $\mathcal{E}_{*} \ominus \Delta_{*}(\zeta) \mathcal{E}_{*}$ for a.e. $\zeta \in \mathbb{T}$, it follows that $\Delta_{*} \Psi\left(I-\Delta_{*}\right)=0$.

For every $u \in \mathcal{H}(\Theta)$, we have

$$
\begin{aligned}
X_{*} C_{\Psi} u & =\Delta_{*} P_{\mathcal{H}(\Theta)} \Psi u=\Delta_{*} \Psi u=\Delta_{*} \Psi\left(\Delta_{*} u+\left(I-\Delta_{*}\right) u\right) \\
& =\Delta_{*} \Psi \Delta_{*} u=\psi \Delta_{*} u=\psi\left(R_{*}\right) X_{*} u .
\end{aligned}
$$

Therefore, $\widehat{\gamma}_{S(\Theta)}\left(C_{\Psi}\right)=\psi$. 


\section{Chapter 4}

\section{Quasianalytic contractions in special classes}

This chapter is devoted to special classes of operators, where quasianalytic contractions naturally arise. Namely, we study analytic contractions in Section 4.1 and bilateral weighted shifts in Section 4.2.

\subsection{Analytic contractions}

In [ARS07] the multiplication operator on a general Hilbert space of analytic functions has been studied. Namely, let $\mathcal{H}_{a}$ be a Hilbert space of analytic functions defined on $\mathbb{D}$, with the usual vector space operations, satisfying the following conditions:

(i) for every $f \in \mathcal{H}_{a}$, we have $\chi f \in \mathcal{H}_{a}$ and $\|\chi f\| \leq\|f\| \quad(\chi(z)=z)$;

(ii) for every $\lambda \in \mathbb{D}$, the evaluation $K_{\lambda}: \mathcal{H}_{a} \rightarrow \mathbb{C}, f \mapsto f(\lambda)$ is a bounded linear functional, and so there is a unique reproducing kernel $k_{\lambda} \in \mathcal{H}_{a}$ with the property $f(\lambda)=\left\langle f, k_{\lambda}\right\rangle \quad\left(f \in \mathcal{H}_{a}\right)$;

(iii) $\mathbb{1} \in \mathcal{H}_{a}$.

The operator $M_{a} \in \mathcal{L}\left(\mathcal{H}_{a}\right), M_{a} f=\chi f$ is called an analytic multiplication operator. Since $M_{a}^{*} k_{\lambda}=\bar{\lambda} k_{\lambda}(\lambda \in \mathbb{D})$ and $\vee\left\{k_{\lambda}: \lambda \in \mathbb{D}\right\}=\mathcal{H}_{a}$, it follows that $M_{a}$ is a

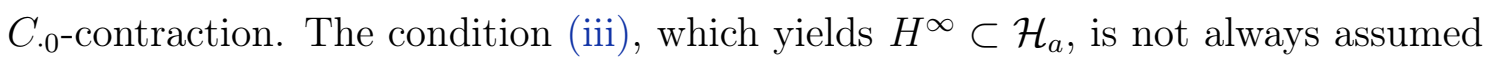
in [ARS07]; we suppose it here for simplicity. The boundary behaviour of functions 
in $\mathcal{H}_{a}$ is governed by the set

$$
\Delta\left(\mathcal{H}_{a}\right)=\left\{\zeta \in \mathbb{T}: \text { nt- } \underline{\lim }_{\lambda \rightarrow \zeta}\left(1-|\lambda|^{2}\right)^{-1}\left\|k_{\lambda}\right\|^{-2}>0\right\}
$$

Namely, it has been shown in [ARS07] that

(a) for every $f \in \mathcal{H}_{a}$, nt- $\lim _{z \rightarrow \zeta} f(z)$ exists for a.e. $\zeta \in \Delta\left(\mathcal{H}_{a}\right)$;

(b) a function $f \in \mathcal{H}_{a}$ can be found so that nt- $\lim _{z \rightarrow \zeta} f(z)$ does not exist for a.e. $\zeta \in \mathbb{T} \backslash \Delta\left(\mathcal{H}_{a}\right)$.

The measurable set $\Delta\left(\mathcal{H}_{a}\right)$ can be related to the quasianalytic spectral set of $M_{a}$.

Proposition 4.1. The inclusion $\Delta\left(\mathcal{H}_{a}\right) \subset \pi\left(M_{a}\right)$ holds. Therefore $M_{a}$ is quasianalytic, whenever $\Delta\left(\mathcal{H}_{a}\right)=\omega\left(M_{a}\right) \neq \emptyset$.

Proof. Setting a non-zero $f \in \mathcal{H}_{a}$, the inequality

$$
\frac{|f(\lambda)|^{2}}{\left(1-|\lambda|^{2}\right)\left\|k_{\lambda}\right\|^{2}} \leq\left(1-|\lambda|^{2}\right)\left\|\left(I-\bar{\lambda} M_{a}\right)^{-1} f\right\| \quad(\lambda \in \mathbb{D})
$$

yields by Proposition 3.6 that

$$
\text { nt- } \varlimsup_{\lambda \rightarrow \zeta} \frac{|f(\lambda)|^{2}}{\left(1-|\lambda|^{2}\right)\left\|k_{\lambda}\right\|^{2}} \leq w_{f, f}(\zeta) \quad \text { for a.e. } \zeta \in \mathbb{T} \text {. }
$$

By Proposition 3.3 of [ARS07] we know that

$$
\text { nt- } \lim _{\lambda \rightarrow \zeta} \frac{|f(\lambda)|^{2}}{\left(1-|\lambda|^{2}\right)\left\|k_{\lambda}\right\|^{2}}>0 \quad \text { for a.e. } \zeta \in \Delta\left(\mathcal{H}_{a}\right) .
$$

Thus $\omega\left(M_{a}, f\right) \supset \Delta\left(\mathcal{H}_{a}\right)$, and so $\Delta\left(\mathcal{H}_{a}\right) \subset \pi\left(M_{a}\right)$; see Proposition 3.1 and Theorem 3.3.

Conditions for the equality $\Delta\left(\mathcal{H}_{a}\right)=\omega\left(M_{a}\right)$ are given in [ARS07].

It is easy to verify that the mapping $\lambda \mapsto k_{\lambda}$ is coanalytic, which means that the function $\varphi(\lambda)=\left\langle f, k_{\lambda}\right\rangle \quad(\lambda \in \mathbb{D})$ is analytic for every $f \in \mathcal{H}_{a}$. Hence $M_{a}$ is an analytic operator in the sense of [CEP89]. We say that $T \in \mathcal{L}(\mathcal{H})$ is an analytic contraction if $\|T\| \leq 1$ and there exists a coanalytic function $\eta: \mathbb{D} \rightarrow \mathcal{H}$ satisfying the conditions:

(i) $T^{*} \eta(\lambda)=\bar{\lambda} \eta(\lambda)$ for every $\lambda \in \mathbb{D}$,

(ii) $\vee\{\eta(\lambda): \lambda \in \mathbb{D}\}=\mathcal{H}$. 
(We note that such contractions are called fully analytic in [CEP89].) The function $\eta$ has an expansion $\eta(\lambda)=\sum_{n=0}^{\infty} \bar{\lambda}^{n} y_{n} \quad(\lambda \in \mathbb{D})$, where

$$
\varlimsup_{n \rightarrow \infty}\left\|y_{n}\right\|^{\frac{1}{n}} \leq 1, \vee\left\{y_{n}\right\}_{n=0}^{\infty}=\mathcal{H}, T^{*} y_{n}=y_{n-1} \text { for } n \in \mathbb{N} \text {, and } T^{*} y_{0}=0
$$

We say that $T$ is a purely analytic contraction, if $\eta$ can be chosen so that $y_{0} \notin$ $\vee\left\{y_{n}\right\}_{n=1}^{\infty}$. It can be easily verified that these are exactly those contractions, which are unitarily equivalent to an analytic multiplication operator. We note also that $T^{*}$ belongs to the Cowen-Douglas class $B_{1}(\mathbb{D})$ introduced in [CD78] if and only if $T$ is an analytic contraction with approximate point spectrum $\sigma_{a p}(T)=\mathbb{T}$ and with Fredholm index ind $T=-1$. Surprisingly, rather general spectral conditions ensure the existence of purely analytic invariant subspaces, i.e. invariant subspaces where the restriction is a purely analytic contraction. Namely, let $T \in \mathcal{L}(\mathcal{H})$ be an a.c. contraction with an isometric functional calculus $\Phi_{T}$, and let us assume that the extended right spectrum

$$
\widetilde{\sigma}_{r}(T)=\mathbb{D} \backslash\{\lambda \in \mathbb{D}:(T-\lambda I) \mathcal{H}=\mathcal{H} \text { and } 0<\operatorname{dim} \operatorname{ker}(T-\lambda I)<\infty\}
$$

is dominating in $\mathbb{D}$, that is a.e. $\zeta \in \mathbb{T}$ is a non-tangential cluster point of $\widetilde{\sigma}_{r}(T)$. Then there is a dense set $\mathcal{H}_{0}$ in $\mathcal{H}$ such that $\vee\left\{T^{n} x\right\}_{n=0}^{\infty}$ is a purely analytic invariant subspace of $T$, for every $x \in \mathcal{H}_{0}$; see [CEP89].

It is not transparent how to identify the unitary asymptote of a general analytic multiplication operator $M_{a}$. This identification can be carried out in the special case when $\mathcal{H}_{a}$ is induced by a measure satisfying particular conditions considered in [ARS09]. Let $\mu$ be a finite positive Borel measure, supported on $\mathbb{D}^{-}$, with the property $\mu(\mathbb{T})>0$. Let $\mathcal{P}$ stand for the algebra of complex polynomials, and let $\mathcal{P}^{2}(\mu)$ denote the closure of $\mathcal{P}$ in $L^{2}(\mu)$. We consider the cyclic subnormal operator $S_{\mu} \in \mathcal{L}\left(\mathcal{P}^{2}(\mu)\right)$, defined by $S_{\mu} f=\chi f$. The following assumptions are made:

(i) $\mathcal{P}^{2}(\mu)$ is irreducible, i.e. $\mathcal{P}^{2}(\mu)$ does not contain non-trivial characteristic function;

(ii) for every $\lambda \in \mathbb{D}$, the evaluation $K_{\lambda}: \mathcal{P} \rightarrow \mathbb{C}, p \mapsto p(\lambda)$ is a bounded linear functional; its continuous extension to $\mathcal{P}^{2}(\mu)$ is represented by $k_{\lambda} \in \mathcal{P}^{2}(\mu)$, i.e. $p(\lambda)=\left\langle p, k_{\lambda}\right\rangle \quad(p \in \mathcal{P})$.

By the results of [ARS09] (see also Chapter VIII in [Con91]), we know that for every $f \in \mathcal{P}^{2}(\mu)$, the function $\tilde{f}(\lambda)=\left\langle f, k_{\lambda}\right\rangle$ is analytic on $\mathbb{D}, \tilde{f}(\lambda)=f(\lambda)$ for 
$\mu$-a.e. $\lambda \in \mathbb{D}$, and for $\mu_{0}$-a.e. $\zeta \in \mathbb{T}$ we have nt- $\lim _{\lambda \rightarrow \zeta} \widetilde{f}(\lambda)=f(\zeta)$. Here $\mu_{0}$ denotes the restriction of $\mu$ to the Borel subsets of $\mathbb{T}$, which is a.c. with respect to $m$. Therefore, $S_{\mu}$ can be considered as an analytic multiplication operator. Furthermore, for $h=\mathrm{d} \mu_{0} / \mathrm{d} m$ we have $h(\zeta)=$ nt- $\varlimsup_{\lambda \rightarrow \zeta}\left(1-|\lambda|^{2}\right)^{-1}\left\|k_{\lambda}\right\|^{-2}$ for a.e. $\zeta \in \mathbb{T}$, and $\Delta\left(\mathcal{P}^{2}(\mu)\right)=\{\zeta \in \mathbb{T}: h(\zeta)>0\}$. It is clear that $(X, V)$ is a unitary asymptote of $S_{\mu}$, where $V \in \mathcal{L}\left(L^{2}\left(\mu_{0}\right)\right), V f=\chi f$ and $X \in \mathcal{L}\left(\mathcal{P}^{2}(\mu), L^{2}\left(\mu_{0}\right)\right)$ is defined by $X f=f \mid \mathbb{T}$. Thus $S_{\mu}$ is asymptotically cyclic. Since $\omega\left(S_{\mu}\right)=\Delta\left(\mathcal{P}^{2}(\mu)\right)$, it follows by Proposition 4.1 that $S_{\mu}$ is quasianalytic.

Proposition 4.2. If $h(\zeta)>0$ for a.e. $\zeta \in \mathbb{T}$, then $S_{\mu} \in \mathcal{L}_{1}\left(\mathcal{P}^{2}(\mu)\right)$ and $\mathcal{F}\left(S_{\mu}\right)=$ $X\left(\mathcal{P}^{2}(\mu) \cap L^{\infty}(\mu)\right)$.

Proof. The equation for $\mathcal{F}\left(S_{\mu}\right)$ follows from Yoshino's theorem; see Theorem II.5.4 in [Con91].

\subsection{Bilateral weighted shifts}

Weighted shifts always serve as a source of examples. Here we consider those bilateral weighted shifts, which are $C_{10}$-contractions. As earlier, $\widetilde{S} \in \mathcal{L}\left(L^{2}(\mathbb{T})\right), \widetilde{S} f=\chi f$ is the simple bilateral shift. The Fourier transformation $F: L^{2}(\mathbb{T}) \rightarrow l^{2}(\mathbb{Z}), f \mapsto \widehat{f}$, where $\widehat{f}(n)=\left\langle f, \chi^{n}\right\rangle \quad(n \in \mathbb{Z})$, is a Hilbert space isomorphism. Let us assume that the sequence $\beta: \mathbb{Z} \rightarrow(0, \infty)$ satisfies the conditions:

(i) $\beta(n) \geq \beta(n+1)$ for every $n \in \mathbb{Z}$,

(ii) $\lim _{n \rightarrow \infty} \beta(-n)=\infty$,

(iii) $)_{0} \lim _{n \rightarrow \infty} \beta(n)>0$.

It is clear that

$$
l^{2}(\beta)=\left\{\xi: \mathbb{Z} \rightarrow \mathbb{C}:\|\xi\|_{\beta}^{2}:=\sum_{n=-\infty}^{\infty}|\xi(n)|^{2} \beta(n)^{2}<\infty\right\}
$$

is a dense linear manifold in $l^{2}(\mathbb{Z})$, which is a Hilbert space with the norm $\|\xi\|_{\beta}$. Hence

$$
L^{2}(\beta)=\left\{f \in L^{2}(\mathbb{T}): \widehat{f} \in l^{2}(\beta)\right\}
$$

is a dense linear manifold in $L^{2}(\mathbb{T})$, which forms a Hilbert space with the norm $\|f\|_{\beta}:=\|\widehat{f}\|_{\beta}$. It can be easily verified that $T_{\beta} \in \mathcal{L}\left(L^{2}(\beta)\right)$, defined by $T_{\beta} f=$ 
$\chi f$, is a $C_{10}$-contraction; see Section IX.2 in [NFBK]. Furthermore, we obtain all bilateral weighted shifts, which are $C_{10}$-contractions, in this way. Since $T_{\beta}$ is unitarily equivalent to $T_{c \beta}(c>0)$, we may assume that $\lim _{n \rightarrow \infty} \beta(n)=1$. Moreover, in that case $T_{\beta}$ is similar to $T_{\widetilde{\beta}}$, where $\widetilde{\beta}(-n)=\beta(-n)$ for $n>0$ and $\widetilde{\beta}(n)=1$ for $n \geq 0$. Therefore, without restricting generality, condition (iii) $)_{0}$ can be replaced by the condition

(iii) $\beta(n)=1$ for every non-negative integer $n \in \mathbb{Z}_{+}$.

Obviously, the pair $\left(X_{\beta}, \widetilde{S}\right)$ is a unitary asymptote of $T_{\beta}$, where $X_{\beta}: L^{2}(\beta) \rightarrow$ $L^{2}(\mathbb{T}), f \mapsto f$ is a quasiaffinity. Thus $T_{\beta}$ is asymptotically cyclic and quasiunitary, with residual set $\omega\left(T_{\beta}\right)=\mathbb{T}$.

The special form of $X_{\beta}$ yields that, for any $\phi \in \mathcal{F}\left(T_{\beta}\right)$, the operator $M_{\phi, \beta}:=$ $\left(\widehat{\gamma}_{T_{\beta}}\right)^{-1}(\phi) \in\left\{T_{\beta}\right\}^{\prime}$ acts as a multiplication: $M_{\phi, \beta} f=\phi f \quad\left(f \in L^{2}(\beta)\right)$. Clearly, $\mathcal{F}\left(T_{\beta}\right) \subset L^{\infty}(\mathbb{T}) \cap L^{2}(\beta)$. The following characterization follows from the Closed Graph Theorem.

Proposition 4.3. The functional commutant $\mathcal{F}\left(T_{\beta}\right)$ consists of the measurable functions $\phi: \mathbb{T} \rightarrow \mathbb{C}$ satisfying the condition $\phi L^{2}(\beta) \subset L^{2}(\beta)$.

The previous discussion shows that $T_{\beta}$ belongs to the class $\mathcal{L}_{1}\left(L^{2}(\beta)\right)$ exactly when the function space $L^{2}(\beta)$ is quasianalytic, that is when $f(\zeta) \neq 0$ for a.e. $\zeta \in \mathbb{T}$ whenever $f$ is a non-zero element of $L^{2}(\beta)$. This happens if $\beta(-n)$ increases sufficiently fast as $n$ tends to infinity.

Proposition 4.4. The function space $L^{2}(\beta)$ is quasianalytic if and only if

$$
\sum_{n=1}^{\infty} n^{-2} \log \beta(-n)=\infty
$$

Proof. Suppose that $\sum_{n=1}^{\infty} n^{-2} \log \beta(-n)=\infty$, and let us consider a non-zero function $f \in L^{2}(\beta)$. For any $n \in \mathbb{N}$, we have

$$
F_{n}:=\left[\sum_{k=n}^{\infty}|\widehat{f}(-k)|^{2}\right]^{\frac{1}{2}} \leq \frac{1}{\beta(-n)}\left[\sum_{k=n}^{\infty}|\widehat{f}(-k)|^{2} \beta(-k)^{2}\right]^{\frac{1}{2}} \leq \frac{\|f\|_{\beta}}{\beta(-n)},
$$

whence

$$
\sum_{n=1}^{\infty} \frac{\log F_{n}}{n^{2}} \leq\left(\log \|f\|_{\beta}\right) \sum_{n=1}^{\infty} \frac{1}{n^{2}}-\sum_{n=1}^{\infty} \frac{\log \beta(-n)}{n^{2}}=-\infty
$$

follows. We infer by Corollary III.4.2 in [Beu77] that $f(\zeta) \neq 0$ for a.e. $\zeta \in \mathbb{T}$. 
Let us assume now that $\sum_{n=1}^{\infty} n^{-2} \log \beta(-n)<\infty$, and set $W(n)=\beta(-|n|)^{2}$ $(n \in \mathbb{Z})$. Since $\sum_{n=-\infty}^{\infty}(\log W(n)) /\left(n^{2}+1\right)<\infty, W(n) \geq 1$ for every $n \in \mathbb{Z}$, and $\lim _{|n| \rightarrow \infty} W(n)=\infty$, we obtain by the Corollary in [Koo98] that there exists a nonidentically zero sequence $\left\{a_{n}\right\}_{n \in \mathbb{Z}}$ of complex numbers such that $\sum_{n=-\infty}^{\infty}\left|a_{n}\right| W(n)<$ $\infty$ and the continuous function $f=\sum_{n=-\infty}^{\infty} a_{n} \chi^{n}$ satisfies the condition $f\left(e^{i t}\right)=0$ whenever $h \leq|t| \leq \pi$. Here $h \in(0, \pi)$ is an arbitrarily prescribed number. Notice that, because of uniform convergence, $\widehat{f}(n)=a_{n}$ for every $n \in \mathbb{Z}$, and so $f$ is nonzero. On the other hand, the relations $\sum_{n=-\infty}^{\infty}|\widehat{f}(n)| \beta(n)^{2} \leq \sum_{n=-\infty}^{\infty}\left|a_{n}\right| W(n)<\infty$ and $\lim _{|n| \rightarrow \infty} \widehat{f}(n)=0$ imply that $\sum_{n=-\infty}^{\infty}|\widehat{f}(n)|^{2} \beta(n)^{2}<\infty$, and so $f \in L^{2}(\beta)$.

The invertibility of $T_{\beta}$ is controlled by the number

$$
\delta_{\beta}:=\inf \{\beta(n+1) / \beta(n): n \in \mathbb{Z}\} \in \mathbb{R}_{+} .
$$

Namely, $T_{\beta}$ is invertible if and only if $\delta_{\beta}>0$. The non-invertible case is well understood.

Proposition 4.5. If $\delta_{\beta}=0$, then $\mathcal{F}\left(T_{\beta}\right)=H^{\infty}$ and so Hlat $T_{\beta}=$ Lat $T_{\beta}$ is nontrivial.

Proof. For reader's convenience we sketch the short proof. Given $\phi \in \mathcal{F}\left(T_{\beta}\right)$, for any $n \in \mathbb{N}$ and $k \in \mathbb{Z}$ we have $\left\langle M_{\phi, \beta} \chi^{k}, \chi^{k-n}\right\rangle_{\beta}=\widehat{\phi}(-n) \beta(k-n)^{2}$, whence $|\widehat{\phi}(-n)| \leq$ $\left\|M_{\phi, \beta}\right\| \beta(k) / \beta(k-n)$ follows. Since $\delta_{\beta}=0$, we infer that $\widehat{\phi}(-n)=0$.

Remark 4.6. (a) If $\beta(-n)=\exp \left(n^{2}\right) \quad(n \in \mathbb{N})$, then $T_{\beta} \in \mathcal{L}_{1}\left(L^{2}(\beta)\right),\left\{T_{\beta}\right\}^{\prime}=$ $H^{\infty}\left(T_{\beta}\right)$, but $T_{\beta}$ is not a quasiaffine transform of $S$, since $T_{\beta}^{*}$ is injective. This example can be contrasted with Proposition 3.13.

(b) The sequence $\beta$ can be chosen so that $\delta_{\beta}=0$ and $\sum_{n=1}^{\infty} \log \beta(-n) / n^{2}<\infty$. In that case the functional commutant $\mathcal{F}\left(T_{\beta}\right)$ is a quasianalytic algebra, while the $C_{10}$-contraction $T_{\beta}$ is not quasianalytic.

Now let us turn to the case when $\delta_{\beta}>0$, and so $\delta_{\beta}=\left\|T_{\beta}^{-1}\right\|^{-1}$. Let $r_{\beta}:=$ $\left(r\left(T_{\beta}^{-1}\right)\right)^{-1}$ be the inner spectral radius of $T_{\beta}$. It is easy to verify that

$$
0<\delta_{\beta} \leq r_{\beta} \leq\left(\varlimsup_{n \rightarrow \infty} \beta(-n)^{\frac{1}{n}}\right)^{-1} \leq\left(\varliminf_{n \rightarrow \infty} \beta(-n)^{\frac{1}{n}}\right)^{-1}=: R_{\beta} \leq 1 .
$$

It is known that the operators of the form $\sum_{n=-N}^{N} c_{n} T_{\beta}^{n}$ are dense in $\left\{T_{\beta}\right\}^{\prime}$ in the strong operator topology, see Corollary (b) in Section 8 of [Shi74]. Thus Hlat $T_{\beta}=$ Lat $T_{\beta} \cap$ Lat $T_{\beta}^{-1}$, and the hyperinvariant subspaces of $T_{\beta}$ may be called biinvariant. 
The case $r_{\beta}=1$ has been settled by Esterle, by providing a subspace $\mathcal{M}$ satisfying condition (ii) of Theorem 3.18. Namely, Theorem 5.7 of [Est97] can be stated in the following way.

Theorem 4.7 (Esterle). If $r_{\beta}=1$, then there exists $\mathcal{M} \in \operatorname{Lat}_{\mathrm{s}} T_{\beta}$ such that $\widetilde{\mathcal{M}}=$ $\vee\left\{C \mathcal{M}: C \in\left\{T_{\beta}\right\}^{\prime}\right\} \neq L^{2}(\beta)$, and so $\widetilde{\mathcal{M}}$ is a non-trivial hyperinvariant subspace of $T_{\beta}$.

For any $R \in(0,1)$, let $A(R):=\{z \in \mathbb{C}: R<|z|<1\}$. It is known that the point spectrum of the adjoint satisfies the condition $A\left(R_{\beta}\right) \subset \sigma_{p}\left(T_{\beta}^{*}\right) \subset A\left(R_{\beta}\right)^{-}$; see Theorem 9 of Section 5 in [Shi74]. Thus the (HSP) for bilateral weighted shifts, which are $C_{10}$-contractions, is open (up to our knowledge) in the case when

$$
0<\delta_{\beta} \leq r_{\beta}<R_{\beta}=1 \text { and } \sum_{n=1}^{\infty} \frac{\log \beta(-n)}{n^{2}}=\infty .
$$

Under these conditions the functional commutant can be related to bounded analytic functions defined on an annulus. For $R \in(0,1)$, let $H^{\infty}(A(R))$ stand for the Banach algebra of bounded analytic functions on $A(R)$. We note that $\mathcal{F}\left(T_{\beta}\right)$ is an abelian Banach algebra with the norm $\|\phi\|_{\beta, \infty}:=\left\|M_{\phi, \beta}\right\|$. In the next statement we consider this norm on $\mathcal{F}\left(T_{\beta}\right)$.

Proposition 4.8. If $0<\delta_{\beta} \leq r_{\beta}<1$, then the mapping

$$
\Lambda_{\beta}: \mathcal{F}\left(T_{\beta}\right) \rightarrow H^{\infty}\left(A\left(r_{\beta}\right)\right), \phi \mapsto \Phi, \text { where } \Phi(z)=\sum_{n=-\infty}^{\infty} \widehat{\phi}(n) z^{n}
$$

is an injective, contractive algebra-homomorphism, while the mapping

$$
\widetilde{\Lambda}_{\beta}: H^{\infty}\left(A\left(\delta_{\beta}\right)\right) \rightarrow \mathcal{F}\left(T_{\beta}\right), \Phi \rightarrow \phi, \text { where } \phi(\zeta)=\mathrm{nt}-\lim _{z \rightarrow \zeta} \Phi(z) \text { for a.e. } \zeta \in \mathbb{T} \text {, }
$$

is a bounded algebra-homomorphism; moreover

$$
\Lambda_{\beta} \widetilde{\Lambda}_{\beta}: H^{\infty}\left(A\left(\delta_{\beta}\right)\right) \rightarrow H^{\infty}\left(A\left(r_{\beta}\right)\right), \Phi \mapsto \Phi \mid A\left(r_{\beta}\right)
$$

In particular, if $0<\delta_{\beta}=r_{\beta}<1$ then $\Lambda_{\beta}$ is an algebra-isomorphism.

Proof. For the sake of completeness we sketch the proof, which is an adaptation of the proof of Theorem 10' in Section 6 of [Shi74] to our situation, avoiding formal series. 
Setting $\phi \in \mathcal{F}\left(T_{\beta}\right)$, the inequality occurring in the proof of Proposition 4.5 shows that

$$
|\widehat{\phi}(-n)| \leq\left\|M_{\phi, \beta}\right\| \inf \{\beta(k) / \beta(k-n): k \in \mathbb{Z}\}=\left\|M_{\phi, \beta}\right\| \cdot\left\|T_{\beta}^{-n}\right\|^{-1} \quad(n \in \mathbb{N}),
$$

whence $\varlimsup_{n \rightarrow \infty}|\widehat{\phi}(-n)|^{1 / n} \leq r_{\beta}$ follows. Hence, the Laurent series $\sum_{n=-\infty}^{\infty} \widehat{\phi}(n) z^{n}$ converges to an analytic function $\Phi$ on $A\left(r_{\beta}\right)$. Let us fix $z \in A\left(r_{\beta}\right)$. Since the linear functional $E_{z}: \mathcal{F}\left(T_{\beta}\right) \rightarrow \mathbb{C}, \phi \mapsto \Phi(z)$ is multiplicative and $\mathcal{F}\left(T_{\beta}\right)$ is an abelian Banach algebra, we infer that $\left\|E_{z}\right\| \leq 1$, and so $|\Phi(z)| \leq\|\phi\|_{\beta, \infty}$. Thus $\Lambda_{\beta}$ is a contractive algebra-isomorphism.

Given any $\Phi \in H^{\infty}\left(A\left(\delta_{\beta}\right)\right)$, let us consider the Laurent expansion $\Phi(z)=$ $\sum_{n=-\infty}^{\infty} c_{n} z^{n}$. The function $\Phi_{+}(z)=\sum_{n=0}^{\infty} c_{n} z^{n}$ is analytic on $\mathbb{D}$, while the function $\Phi_{-}(z)=\sum_{n=1}^{\infty} c_{-n} z^{-n}$ is analytic on $\overline{\mathbb{C}} \backslash\left(\delta_{\beta} \mathbb{D}\right)^{-}$. For any $r \in\left(\delta_{\beta}, 1\right), \Phi_{-}$is bounded on $A(r)$, hence $\Phi_{+}=\Phi-\Phi_{-}$is bounded on $A(r)$, and so $\Phi_{+}$is bounded on $\mathbb{D}$. By Fatou's theorem $\phi(\zeta)=$ nt- $\lim _{z \rightarrow \zeta} \Phi(z)=\left(\right.$ nt- $\left.\lim _{z \rightarrow \zeta} \Phi_{+}(z)\right)+\Phi_{-}(\zeta)$ exists for a.e. $\zeta \in \mathbb{T}$. Setting $\phi_{r}(\zeta)=\Phi(r \zeta)\left(r \in\left(\delta_{\beta}, 1\right), \zeta \in \mathbb{T}\right)$, Lebesgue's dominating convergence theorem yields that $\widehat{\phi}(n)=\lim _{r \rightarrow 1} \widehat{\phi}_{r}(n)=c_{n} r^{n}=c_{n}$ for every $n \in \mathbb{Z}$. (This argument shows that $\phi$ can be recovered from $\Lambda_{\beta} \phi$, and so $\Lambda_{\beta}$ is injective.)

For any $N \in \mathbb{N}$, set $\sigma_{N}=\sum_{n=-N}^{N}\left(1-\frac{|n|}{N+1}\right) c_{n} \chi^{n}$. By a von Neumann-type inequality for annulus we know that

$$
\left\|\sigma_{N}\left(T_{\beta}\right)\right\| \leq C_{\beta} \sup \left\{\left|\sigma_{N}(z)\right|: z \in A\left(\delta_{\beta}\right)\right\},
$$

where $C_{\beta}$ depends only on $\delta_{\beta}$; see Proposition 23 in Section 6 of [Shi74]. Since $\left|\sigma_{N}(r \zeta)\right| \leq\left\|\phi_{r}\right\|_{\infty} \leq\|\Phi\|_{\infty}$ for $r \in\left(\delta_{\beta}, 1\right)$ and $\zeta \in \mathbb{T}$, it follows that the sequence $\left\{M_{\sigma_{N}, \beta}=\sigma_{N}\left(T_{\beta}\right)\right\}_{N=1}^{\infty}$ of operators is bounded. Taking into account that $\left\langle\sigma_{N} \chi^{k}, \chi^{l}\right\rangle_{\beta}=\widehat{\sigma}_{N}(l-k) \beta(l)^{2}$ converges to $c_{l-k} \beta(l)^{2}$ as $N \rightarrow \infty \quad(k, l \in \mathbb{Z})$, we conclude that $M_{\sigma_{N}, \beta} \in\left\{T_{\beta}\right\}^{\prime}$ converges in the weak operator topology to an operator $M_{\psi, \beta}$ with $\psi \in \mathcal{F}(T)$, as $N \rightarrow \infty$. Since $\widehat{\psi}(l-k) \beta(l)^{2}=\lim _{N \rightarrow \infty}\left\langle\sigma_{N} \chi^{k}, \chi^{l}\right\rangle_{\beta}=$ $c_{l-k} \beta(l)^{2} \quad(k, l \in \mathbb{Z})$, we obtain that $\widehat{\psi}(n)=c_{n}=\widehat{\phi}(n) \quad(n \in \mathbb{Z})$, and so $\phi=\psi \in$ $\mathcal{F}\left(T_{\beta}\right)$. Clearly, $\|\phi\|_{\beta, \infty} \leq C_{\beta}\|\Phi\|_{\infty}$ which means that $\widetilde{\Lambda}_{\beta}$ is a bounded algebrahomomorphism. The relation $\left(\Lambda_{\beta} \circ \widetilde{\Lambda}_{\beta}\right) \Phi=\Phi \mid A\left(r_{\beta}\right)$ readily follows from the previous discussions. 


\section{Chapter 5}

\section{Spectral behaviour of quasianalytic contractions}

Though (ISP) and (HSP) are open for asymptotically non-vanishing (a.n.v.) contractions, Corollary 3.4 shows that these questions are settled in the non-quasianalytic case. By this fact it becomes crucial to determine the spectral behaviour of quasianalytic contractions. Namely, if an a.n.v. contraction $T$ does not meet this behaviour, then $T$ is not quasianalytic, and so Hlat $T$ is non-trivial.

If the contraction $T$ is quasianalytic, then it is of class $C_{10}$; see Theorem 3.8. Under this asymptotic behaviour there is a connection between the spectrum $\sigma(T)$ of $T$ and the spectrum $\sigma(V)$ of its unitary asymptote $V$. First we note that $\sigma(V)$ is the essential support of $\omega(T): \sigma(V)=\mathrm{es}(\omega(T))$, which is the complement of the largest open subset $\mathcal{O}$ of $\mathbb{T}$ with the property $m(\mathcal{O} \cap \omega(T))=0$. It can be easily proved that $\sigma(V)$ is neatly contained in $\sigma(T)$, that is $\sigma(V) \subset \sigma(T)$ and $m\left(\sigma(V) \cap \sigma^{\prime}\right)>0$ holds for every non-empty closed subset $\sigma^{\prime}$ of $\sigma(T)$ with the property that $\sigma(T) \backslash \sigma^{\prime}$ is also closed. More importantly, this is the only constraint on the spectrum of a $C_{10}$-contraction, even in the cyclic case, that is when $\vee_{n=0}^{\infty} T^{n} h=\mathcal{H}$ holds with some vector $h \in \mathcal{H}$; see Chapter IX in [NFBK]. Are there any other constraints if $T$ is quasianalytic? More precisely, we pose the following problem.

Question 1. Given a measurable set $\omega_{0} \subset \mathbb{T}$ of positive measure and a compact subset $\sigma$ of the closed unit disc $\mathbb{D}^{-}$such that es $\left(\omega_{0}\right)$ is neatly contained in $\sigma$, does a quasianalytic contraction $T$ exist with the properties $\sigma(T)=\sigma$ and $\omega(T)=\omega_{0}$ ?

In the $C_{10}$ class the construction starts by producing a $C_{10}$-contraction $T$ satisfying the conditions $\omega(T)=\omega_{0}$ and $\sigma(T)=\mathrm{es}\left(\omega_{0}\right)$, as a restriction of a bilat- 
eral weighted shift $W$ to an appropriately chosen invariant subspace. However, if $m\left(\mathbb{T} \backslash \omega_{0}\right)>0$ then $W$ is necessarily non-quasianalytic; otherwise $\pi(T)=\pi(W)=\mathbb{T}$ would happen. Furthermore, the coincidence $\sigma(T)=\operatorname{es}(\omega(T))$ is ensured by the condition $\sum_{n=1}^{\infty} n^{p}\left\|T^{-n}\right\|<\infty$ with some integer $p$. However, this relation implies the existence of an operator $C \in\{T\}^{\prime}$ and a non-zero continuous function $f$ on $\mathbb{T}$ such that $X C=f(V) X$ and the set $\{\zeta \in \omega(T): f(\zeta)=0\}$ has positive measure, less than $m(\omega(T))$; see Lemma IX.2.11 and its proof in [NFBK]. Hence we can present a non-zero vector $h \in \mathcal{H}$ such that $X h$ is not cyclic for the commutant $\{V\}^{\prime}$, which is impossible if $T$ is quasianalytic; see Theorem 16 in [Kér01]. Therefore, we have to find another approach to provide a quasianalytic contraction $T$, if it exists at all, such that its spectrum $\sigma(T)$ is a proper subset of $\mathbb{T}$. First of all the following simpler question should be answered.

Question 2. Do we have for every closed arc $J$ of positive measure on $\mathbb{T}$ and for every $c>0$ a quasianalytic contraction $T$ satisfying the conditions $\sigma(T)=\pi(T)=J$ and $\left\|T^{-1}\right\|>c$ ?

We know that the a.c. contraction $T$ has shift-type invariant subspaces if $\omega(T)=$ $\mathbb{T}$. Namely, $\mathcal{H}=\vee \operatorname{Lat}_{\mathrm{s}} T$, where $\operatorname{Lat}_{\mathrm{s}} T$ consists of those invariant subspaces $\mathcal{M}$ where $T \mid \mathcal{M}$ is similar to the simple unilateral shift $S \in \mathcal{L}\left(H^{2}\right), S f=\chi f(\chi(\zeta)=\zeta)$; see Theorem IX.3.6 in [NFBK]. Any quasianalytic contraction can be related to such a contraction having a rich invariant subspace lattice.

Theorem 5.1. For every quasianalytic contraction $T_{1}$, there exists a quasianalytic contraction $T_{2}$ with $\pi\left(T_{2}\right)=\mathbb{T}$ such that $\left\{T_{2}\right\}^{\prime} \supset\left\{T_{1}\right\}^{\prime}$ and so Hlat $T_{2} \subset$ Hlat $T_{1}$.

Proof. By Theorem 3 of [KT12] there exist a compact set $K \subset \pi\left(T_{1}\right)$ and a continuous function $f$ on $\mathbb{D}^{-}$such that $f$ is analytic (even univalent) on $\mathbb{D}, f^{-1}(\mathbb{T})=K$ and $m(f(\alpha))=0$ for every Borel subset $\alpha$ of $K$ of zero measure. Then $\pi\left(T_{2}\right)=\mathbb{T}$ holds for the a.c. contraction $T_{2}=f\left(T_{1}\right)$ by Corollary 2.5 of [Kér11] (see also Lemma 5 in [KT12]). It is obvious that $\left\{T_{2}\right\}^{\prime} \supset\left\{T_{1}\right\}^{\prime}$.

Therefore, the (HSP) for a.n.v. contractions can be reduced to the case, when $T$ is quasianalytic and $\pi(T)=\mathbb{T}$. Clearly, $\mathbb{T}$ is neatly contained in $\sigma(T)$ exactly when $\sigma(T)$ is connected. Thus, in this particular class Question 1 has the following modified form. 
Question 3. Given a connected, compact subset $\sigma$ of $\mathbb{D}^{-}$, containing $\mathbb{T}$, does there exist a quasianalytic contraction $T$ satisfying the conditions $\sigma(T)=\sigma$ and $\pi(T)=$ $\mathbb{T} ?$

The preceding two questions are related. Let $\mathbb{D}_{+}:=\{z \in \mathbb{D}: \operatorname{Im} z>0\}$, $\mathbb{T}_{+}:=\{\zeta \in \mathbb{T}: \operatorname{Im} \zeta \geq 0\}$, and for any $K \subset \mathbb{C}$ let $K^{2}:=\left\{z^{2}: z \in K\right\}$.

Theorem 5.2. A positive answer for Question 2 implies an affirmative answer for Question 3 in the special case, when $\sigma=K^{2}$ for some connected, compact set $K$ such that $\mathbb{T}_{+} \subset K \subset \mathbb{D}_{+}^{-}$.

Proof. Let $K$ be a connected, compact set such that $\mathbb{T}_{+} \subset K \subset \mathbb{D}_{+}^{-}$and $K^{2}=\sigma$. We apply the technique used in Section IX.2 of [NFBK] to obtain a quasianalytic contraction $\widetilde{T}$ satisfying the conditions $\sigma(\widetilde{T})=K$ and $\pi(\widetilde{T})=\mathbb{T}_{+}$.

Let $\left\{\lambda_{n}\right\}_{n=1}^{\infty}$ be a dense sequence in $K$. For every $n \in \mathbb{N}$, let us consider the connected, open set $\Omega_{n}=\{z \in \mathbb{C}: \operatorname{dist}(z, K)<1 / n\}$, and select a point $\lambda_{n}^{\prime} \in \mathbb{D} \cap \Omega_{n}$ so that $\left|\lambda_{n}-\lambda_{n}^{\prime}\right|<1 /(2 n)$. Let $\Gamma_{n} \subset\left(\Omega_{n} \cap \mathbb{D}\right) \cup\{-1,1\}$ be a simple rectifiable curve, with endpoints -1 and 1 , such that the simply connected domain $G_{n}$ bounded by $\mathbb{T}_{+} \cup \Gamma_{n}$ is contained in $\Omega_{n}$ and $\lambda_{n}^{\prime} \in G_{n}$. There exists a conformal mapping $f_{n}: \mathbb{D} \rightarrow$ $G_{n}$, having continuous extension onto $\mathbb{D}^{-}$, such that $f_{n}(0)=\lambda_{n}^{\prime}$. Let us consider the closed arc $J_{n}=f_{n}^{-1}\left(\mathbb{T}_{+}\right)$. By our assumption there exists a quasianalytic contraction $T_{n} \in \mathcal{L}\left(\mathcal{H}_{n}\right)$ such that $\sigma\left(T_{n}\right)=\pi\left(T_{n}\right)=J_{n}$ and $\left\|T_{n}^{-1}\right\|>n$. Then $\widetilde{T}_{n}=f_{n}\left(T_{n}\right)$ is also a quasianalytic contraction with the properties $\sigma\left(\widetilde{T}_{n}\right)=\pi\left(\widetilde{T}_{n}\right)=\mathbb{T}_{+}$; see Proposition IX.2.4 in [NFBK] and Corollary 2.5 in [Kér11].

Setting $\widetilde{T}=\sum_{n=1}^{\infty} \oplus \widetilde{T}_{n}$, we may verify that $\sigma(\widetilde{T})=K$ and $\pi(\widetilde{T})=\mathbb{T}_{+}$. Indeed, for every $n \in \mathbb{N}$, there exists a unit vector $e_{n} \in \mathcal{H}_{n}$ such that $\left\|T_{n} e_{n}\right\|<1 / n$. Since $f_{n}(z)-\lambda_{n}^{\prime}=z g_{n}(z)$, where $\left\|g_{n}\right\|_{\infty} \leq 2$, it follows that $\left\|\widetilde{T}_{n} e_{n}-\lambda_{n}^{\prime} e_{n}\right\|=$ $\left\|g_{n}\left(T_{n}\right) T_{n} e_{n}\right\| \leq 2 / n$. Taking into account that each $\lambda \in K$ is a cluster point of the sequence $\left\{\lambda_{n}^{\prime}\right\}_{n=1}^{\infty}$, we infer that $K \subset \sigma(\widetilde{T})$. On the other hand, if $\lambda \notin K$ then $\delta_{0}=\operatorname{dist}\left(\lambda, G_{n_{0}}\right)>0$ for some $n_{0} \in \mathbb{N}$. Thus, $\left\|\left(\widetilde{T}_{n}-\lambda I\right)^{-1}\right\| \leq\left\|1 /\left(f_{n}-\lambda\right)\right\|_{\infty} \leq 1 / \delta_{0}$ holds whenever $n \geq n_{0}$. Since $\lambda \notin \sigma\left(\widetilde{T}_{n}\right)$ for all $n$, it follows that $\lambda \notin \sigma(\widetilde{T})$. Therefore, $\sigma(\widetilde{T})=K$. Finally, $\pi(\widetilde{T})=\cap_{n=1}^{\infty} \pi\left(\widetilde{T}_{n}\right)=\mathbb{T}_{+}$is obvious. Now, $T=\widetilde{T}^{2}$ is a quasianalytic contraction satisfying the conditions $\sigma(T)=K^{2}=\sigma$ and $\pi(T)=$ $\mathbb{T}_{+}^{2}=\mathbb{T}$.

Remark 5.3. Not every connected, compact set $\mathbb{T} \subset \sigma \subset \mathbb{D}^{-}$can be represented as $\sigma=K^{2}$ with a connected, compact set $\mathbb{T}_{+} \subset K \subset \mathbb{D}_{+}^{-}$. Indeed, let $\rho:[0,1) \rightarrow[0, \infty)$ 
and $\varphi:[0,1) \rightarrow[0, \infty)$ be strictly increasing, continuous functions satisfying the conditions $\rho(0)=\varphi(0)=0, \lim _{t \rightarrow 1-} \rho(t)=1, \lim _{t \rightarrow 1-} \varphi(t)=\infty$, and take the connected compact set $\sigma=\mathbb{T} \cup\left\{\rho(t) e^{i \varphi(t)}: t \in[0,1)\right\}$.

Clearly, the (ISP) can be reduced to the case when $T$ is asymptotically cyclic. Therefore, it is important to know the spectral behaviour in this setting too. In the class $\mathcal{L}_{0}(\mathcal{H})$ of asymptotically cyclic quasianalytic contractions and $\mathcal{L}_{1}(\mathcal{H})=\{T \in$ $\left.\mathcal{L}_{0}(\mathcal{H}): \pi(T)=\mathbb{T}\right\}$ the same commutants arise and (HSP) can be reduced to $\mathcal{L}_{1}(\mathcal{H})$ by Theorem 3.15. This fact makes it especially important to answer the following question.

Question 4. What are the possible spectra of the contractions belonging to $\mathcal{L}_{1}(\mathcal{H})$ ?

We know that for every $0 \leq \delta<1$ there is a contraction $T_{\delta} \in \mathcal{L}_{1}(\mathcal{H})$ such that $\sigma\left(T_{\delta}\right)=\{z \in \mathbb{C}: \delta \leq|z| \leq 1\}$; see Example 3.24. Now we show that the spectrum can be the unit circle $\mathbb{T}$ too. The following theorem gives positive answer also for Question 2 in the special case, when the arc $J$ is the whole circle $\mathbb{T}$.

Theorem 5.4. For every $c>1$, there is a contraction $T \in \mathcal{L}_{1}(\mathcal{H})$ such that $\sigma(T)=$ $\mathbb{T}$ and $\left\|T^{-1}\right\| \geq c$.

Proof. We present a bilateral weighted shift with the prescribed properties. Let $\beta: \mathbb{Z} \rightarrow[1, \infty)$ be a sequence such that $\beta(n)=1$ for all $n \geq 0$ and $\beta(-n)=e^{\varphi(n)}$ for $n \in \mathbb{N}$, where the increasing sequence $\varphi: \mathbb{N} \rightarrow[1, \infty)$ with $\lim _{n \rightarrow \infty} \varphi(n)=\infty$ is specified later. Let $\sum_{n=-\infty}^{\infty} \widehat{f}(n) \chi^{n}$ stand for the Fourier series of the function $f \in L^{2}(\mathbb{T})$, where $\chi(\zeta)=\zeta \quad(\zeta \in \mathbb{T})$. We consider the Hilbert space $L^{2}(\beta)=$ $\left\{f \in L^{2}(\mathbb{T}):\|f\|_{\beta}^{2}:=\sum_{n=-\infty}^{\infty}|\widehat{f}(n)|^{2} \beta(n)^{2}<\infty\right\}$ and the asymptotically cyclic $C_{10}$-contraction $T_{\beta} \in \mathcal{L}\left(L^{2}(\beta)\right)$, defined by $T_{\beta} f=\chi f$.

Now we specify the sequence $\varphi$ so that $T_{\beta}$ be quasianalytic with $\sigma\left(T_{\beta}\right)=\mathbb{T}$. Select a strictly decreasing sequence $\left\{q_{k}\right\}_{k=1}^{\infty}$ of real numbers in $(0,1)$ such that $\lim _{k \rightarrow \infty} q_{k}=0$, and then select a strictly increasing sequence $\left\{p_{k}\right\}_{k=1}^{\infty}$ of positive integers satisfying the conditions $p_{1}=1$ and $\sum_{n=p_{k}+1}^{p_{k+1}} \frac{1}{n} \geq 1 / q_{k}$ for every $k \in \mathbb{N}$. Setting $c>1$, let $\varphi(1):=c$, and for any $k \in \mathbb{N}$ and $p_{k}<n \leq p_{k+1}$ let $\varphi(n):=$ $\varphi\left(p_{k}\right)+\left(n-p_{k}\right) q_{k}$. Clearly, $\varphi$ is increasing. It can be verified by induction that 
$\varphi\left(p_{k}\right) \geq p_{k} q_{k}$ holds for every $k \in \mathbb{N}$. Thus $\varphi(n) \geq n q_{k}$ if $p_{k}<n \leq p_{k+1}$, whence

$$
\begin{aligned}
\sum_{n=1}^{\infty} \frac{\log \beta(-n)}{n^{2}} & =\sum_{n=1}^{\infty} \frac{\varphi(n)}{n^{2}}=c+\sum_{k=1}^{\infty} \sum_{n=p_{k}+1}^{p_{k+1}} \frac{\varphi(n)}{n^{2}} \\
& \geq \sum_{k=1}^{\infty} q_{k} \sum_{n=p_{k}+1}^{p_{k+1}} \frac{1}{n} \geq \sum_{k=1}^{\infty} 1=\infty
\end{aligned}
$$

follows. We conclude that $T_{\beta}$ is quasianalytic, and so $T_{\beta} \in \mathcal{L}_{1}\left(L^{2}(\beta)\right)$; see Proposition 4.4 .

Since the sequence $\left\{q_{k}\right\}_{k=1}^{\infty}$ is decreasing, it follows that

$$
\left\|T_{\beta}^{-n}\right\|=\sup \left\{\frac{\beta(j-n)}{\beta(j)}: j \in \mathbb{Z}\right\}=e^{\varphi(n)} \quad \text { for all } n \in \mathbb{N} .
$$

In particular, we get $\left\|T_{\beta}^{-1}\right\|=e^{\varphi(1)}=e^{c} \geq c$. Furthermore, for every $k \in \mathbb{N}$ and $p_{k}<n \leq p_{k+1}$ we have

$$
0 \leq \frac{\varphi(n)}{n}=\frac{\varphi\left(p_{k}\right)}{n}+\frac{n-p_{k}}{n} q_{k} \leq \frac{\varphi\left(p_{k}\right)}{p_{k}}+q_{k}
$$

Hence $\lim _{n \rightarrow \infty} \varphi(n) / n=0$ holds, if $\lim _{k \rightarrow \infty} \varphi\left(p_{k}\right) / p_{k}=0$. The inequality

$$
\frac{1}{q_{k}} \leq \sum_{n=p_{k}+1}^{p_{k+1}} \frac{1}{n} \leq \int_{p_{k}}^{p_{k+1}} \frac{\mathrm{d} x}{x}=\ln \frac{p_{k+1}}{p_{k}}
$$

yields that

$$
\frac{p_{k}}{p_{k+1}} \leq e^{-\frac{1}{q_{k}}} \leq \frac{1}{2}
$$

Applying the recursive formula

$$
\frac{\varphi\left(p_{k+1}\right)}{p_{k+1}}=\frac{\varphi\left(p_{k}\right)}{p_{k}} \cdot \frac{p_{k}}{p_{k+1}}+\left(1-\frac{p_{k}}{p_{k+1}}\right) q_{k}
$$

we can check by induction that $\varphi\left(p_{k}\right) / p_{k} \leq 2 c$ holds for all $k \in \mathbb{N}$. The previous inequalities imply that

$$
\frac{\varphi\left(p_{k+1}\right)}{p_{k+1}} \leq 2 c e^{-\frac{1}{q_{k}}}+q_{k},
$$

whence $\lim _{k \rightarrow \infty} \varphi\left(p_{k}\right) / p_{k}=0$ immediately follows. Therefore, the spectral radius of $T_{\beta}^{-1}$ is

$$
r\left(T_{\beta}^{-1}\right)=\lim _{n \rightarrow \infty}\left\|T_{\beta}^{-n}\right\|^{\frac{1}{n}}=\lim _{n \rightarrow \infty} e^{\varphi(n) / n}=1 .
$$

In view of the circular symmetry of $\sigma\left(T_{\beta}\right)$ we obtain that $\sigma\left(T_{\beta}\right)=\mathbb{T}$.

Relying on this statement we can provide contractions in $\mathcal{L}_{1}(\mathcal{H})$ with more sophisticated spectra. 
Example 5.5. (a) Given any $\delta \in(0,1)$, let us consider the domain $\Omega_{\delta}=\{z=$ $r e^{i t}: \sqrt{\delta}<r<1$ and $\left.0<t<\pi\right\}$. Let $\eta_{\delta}$ be a conformal mapping of $\mathbb{D}$ onto $\Omega_{\delta}$, and set $\vartheta_{\delta}=\eta_{\delta}^{2}$. If $T \in \mathcal{L}_{1}(\mathcal{H})$ is an operator with $\sigma(T)=\mathbb{T}$, then $T_{\delta}=\vartheta_{\delta}(T) \in \mathcal{L}_{1}(\mathcal{H})$ and $\sigma\left(T_{\delta}\right)=\mathbb{T} \cup \delta \mathbb{T} \cup[\delta, 1]$. Observe that $\mathbb{D} \backslash \sigma\left(T_{\delta}\right)$ is not connected.

(b) We recall that a domain $\Omega \subset \mathbb{C}$ is called a circular comb domain, if it is of the form $\Omega=\mathbb{D} \backslash\{r \zeta: \zeta \in H, \rho(\zeta)<r<1\}$, where $H \subset \mathbb{T}$ is countable and $\rho: H \rightarrow(0,1)$. Let $K$ be a Cantor-type compact set on $\mathbb{T}$ of positive measure. In view of Theorem 3 of [KT12] we know that there exists a compact set $\widetilde{K} \subset K$ and a conformal mapping $f$ of $\mathbb{D}$ onto a circular comb domain $\Omega$ such that $f$ can be continuously extended onto $\mathbb{D}^{-}, f^{-1}(\mathbb{T})=\widetilde{K}$, and $m(f(\alpha))=0$ whenever $\alpha \subset \widetilde{K}$ is of measure zero. If $T \in \mathcal{L}_{1}(\mathcal{H})$ with $\sigma(T)=\mathbb{T}$, then the spectrum of $\widetilde{T}=f(T) \in$ $\mathcal{L}_{1}(\mathcal{H})$ is $\sigma(\widetilde{T})=\mathbb{T} \cup\{r \zeta: \zeta \in H, \rho(\zeta) \leq r<1\}$, where $H$ is dense in $\mathbb{T}$.

Questions 1-4, in their full generality, remain open. 


\section{Summary}

In this thesis we study the asymptotic behaviour and basic structure of Hilbert space contractions. The dissertation contains two different topics concerning absolutely continuous contractions.

In Chapter 2 we study stability properties of contractions and polynomially bounded operators. In Section 2.1 we characterize those sequences $\left\{h_{n}\right\}_{n=1}^{\infty}$ of bounded analytic functions, which can serve to test the stability of an a.c. contraction, namely, satisfying the condition that $h_{n}(T) \rightarrow 0$ (SOT) if and only if $T \in C_{0}$. We call such a sequence a test sequence of stability for a.c. contractions and it turns out that they are exactly those sequences which fulfill the following three conditions:

(i) $\lim _{n \rightarrow \infty} h_{n}(z)=0$ for all $z \in \mathbb{D}$,

(ii) $\sup \left\{\left\|h_{n}\right\|_{\infty}: n \in \mathbb{N}\right\}<\infty$,

(iii) $\lim \sup _{n \rightarrow \infty}\left\|\chi_{\alpha} h_{n}\right\|_{2}>0$ for every Borel set $\alpha \subset \mathbb{T}$ of positive measure, where $\chi_{\alpha}$ is the characteristic function of $\alpha$.

We prove some connected results too. In Section 2.2 analogous questions for polynomially bounded operators are examined. We prove that test sequences for a.c. polynomially bounded operators are the same as for contractions.

The remaining chapters are mainly motivated by the famous invariant and hyperinvariant subspace problems, we investigate special types of asymptotically nonvanishing contractions. One can attach unitary operators to this type of contractions, and then examine how the properties of the well-understood unitaries reflect in the behaviour of the contractions under consideration. By the concept of a unitary asymptote the residual set, while by the aid of the minimal unitary dilation and the Sz.-Nagy-Foias functional calculus, the quasianalytic spectral set can be defined. 
In the beginning of Chapter 3, namely, in Section 3.1 we introduce local version of the quasianalytic spectral set and exhibit its connection with the residual set. It turns out that local stability is determined by the asymptotic density function, and that the local residual set and the local quasianalytic spectral set at a vector are the same, and hence the (global) quasianalytic spectral set is always contained in the residual set. If this containment is proper for some $T$, then Hlat $T$ is nontrivial. In the case of equality $T$ is called quasianalytic. Investigation of this type of contractions is the main part of the dissertation. In Section 3.2 the fundamental properties of quasianalytic contractions are summarized including their asymptotic behaviour. In the setting of quasianalytic contractions (ISP) can be reduced to the the class $\mathcal{L}_{0}(\mathcal{H})$ of asymptotically cyclic quasianalytic contractions, i.e. quasianalytic contractions with cyclic unitary asymptotes. They are studied in Section 3.3, where equivalent conditions are given for the existence of a non-trivial hyperinvariant subspace. (HSP) in $\mathcal{L}_{0}(\mathcal{H})$, by virtue of Theorem 3.15, can be reduced to the class $\mathcal{L}_{1}(\mathcal{H})=\left\{T \in \mathcal{L}_{0}(\mathcal{H}): \pi(T)=\mathbb{T}\right\}$, in which class we have a lot of information on the structure of a contraction. By Theorem 3.12, there are lots of shift-type invariant subspaces in this class. Therefore, if $\{T\}^{\prime}=H^{\infty}(T)$, then Hlat $T=\operatorname{Lat} T$ is non-trivial. However, if $\{T\}^{\prime} \neq H^{\infty}(T)$, then the shift-type invariant subspaces are not hyperinvariant. On the other hand, if non-trivial hyperinvariant subspaces exist, then, according to Theorem 3.18, such subspaces can be derived from shifttype invariant subspaces. We show that if $\{T\}^{\prime} \neq H^{\infty}(T)$, then $T$ is necessarily quasiunitary, hence (HSP) in $\mathcal{L}_{1}(\mathcal{H})$ can be reduced to the quasiunitary case.

For an asymptotically cyclic quasianalytic contraction $T$, the commutant $\{T\}^{\prime}$ can be identified with a function algebra $\mathcal{F}(T) \subset L^{\infty}(\mathbb{T})$, the so-called functional commutant. Answering a question posed in [Kér11] we show in Section 3.4 that $\mathcal{F}(T)$ can be a pre-Douglas algebra only in the case when $\mathcal{F}(T)=H^{\infty}$. We prove also similarity invariance of $\mathcal{F}(T)$ and detect its representation in the functional model.

Chapter 4 is devoted to special classes of operators, where quasianalytic contractions naturally arise. Namely, we study analytic contractions and bilateral weighted shifts.

In [ARS07], on a general Hilbert space $\mathcal{H}_{a}$ of analytic functions defined on the unit disc $\mathbb{D}$, the analytic multiplication operator $M_{a} \in \mathcal{L}\left(\mathcal{H}_{a}\right), M_{a} f=\chi f$ has been 
studied. The boundary behaviour of functions in $\mathcal{H}_{a}$ is governed by the set

$$
\Delta\left(\mathcal{H}_{a}\right)=\left\{\zeta \in \mathbb{T}: \text { nt- } \underline{\lim }_{\lambda \rightarrow \zeta}\left(1-|\lambda|^{2}\right)^{-1}\left\|k_{\lambda}\right\|^{-2}>0\right\}
$$

where $k_{\lambda} \in \mathcal{H}_{a}$ is the unique reproducing kernel with the property $f(\lambda)=\left\langle f, k_{\lambda}\right\rangle$ for every $f \in \mathcal{H}_{a}$. We show in Section 4.1 that the measurable set $\Delta\left(\mathcal{H}_{a}\right)$ is always contained in the quasianalytic spectral set of $M_{a}$. Therefore, the conditions for the equality $\Delta\left(\mathcal{H}_{a}\right)=\omega\left(M_{a}\right)$ given in [ARS07] ensures the quasianalycity of $M_{a}$. It is not transparent how to identify the unitary asymptote of a general analytic multiplication operator $M_{a}$. This identification can be carried out in the special case when $\mathcal{H}_{a}$ is induced by a measure satisfying particular conditions considered in [ARS09].

In Section 4.2 we deal with bilateral weighted shifts, which are $C_{10}$ contractions, mainly applying the ideas of [Shi74], but working with actual functions instead of formal series. Without restricting the generality, we can suppose that the bilateral weighted shift in consideration is asymptotically cyclic and quasiunitary. We realize a bilateral weighted shift $T_{\beta}$ as multiplication by the identical function on a function space $L^{2}(\beta)$. Up to our knowledge, (HSP) for bilateral weighted shifts, which are $C_{10}$ contractions, is open in the case when

$$
0<\delta_{\beta} \leq r_{\beta}<R_{\beta}=1 \quad \text { and } \quad \sum_{n=1}^{\infty} \frac{\log \beta(-n)}{n^{2}}=\infty .
$$

Here $\delta_{\beta}>0$ means that $T_{\beta}$ is invertible, $r_{\beta}$ denotes the inner spectral radius of $T_{\beta}$, while the growth condition on $\beta(-n)$ ensures the quasianalycity of the function algebra $L^{2}(\beta)$. Under these conditions the functional commutant can be related to bounded analytic functions defined on an annulus.

Though (ISP) and (HSP) are open for asymptotically non-vanishing (a.n.v.) contractions, Corollary 3.4 shows that these questions are settled in the non-quasianalytic case. By this fact it becomes crucial to determine the spectral behaviour of quasianalytic contractions. Namely, if an a.n.v. contraction $T$ does not meet this behaviour, then $T$ is not quasianalytic, and so Hlat $T$ is non-trivial.

If the contraction $T$ is quasianalytic, then it is of class $C_{10}$. Under this asymptotic behaviour there is a connection between the spectrum $\sigma(T)$ of $T$ and the spectrum $\sigma(V)$ of its unitary asymptote $V$. Namely, $\sigma(V)$ is the essential support of $\omega(T)$ (in notation $\sigma(V)=\operatorname{es}(\omega(T)))$ and it is neatly contained in $\sigma(T)$, that is $\sigma(V) \subset \sigma(T)$ and $m\left(\sigma(V) \cap \sigma^{\prime}\right)>0$ holds for every non-empty closed subset $\sigma^{\prime}$ of $\sigma(T)$ with the 
property that $\sigma(T) \backslash \sigma^{\prime}$ is also closed. More importantly, this is the only constraint on the spectrum of a $C_{10}$-contraction, even in the cyclic case, that is when $\vee_{n=0}^{\infty} T^{n} h=\mathcal{H}$ holds with some vector $h \in \mathcal{H}$; see Chapter IX in [NFBK]. In Chapter 5 we examine whether there are any other constraints if $T$ is quasianalytic. We pose four questions and give partial answers.

We prove that if for every closed arc $J$ of positive measure on $\mathbb{T}$ and for every $c>0$ there exists a quasianalytic contraction $T$ satisfying the conditions $\sigma(T)=$ $\pi(T)=J$ and $\left\|T^{-1}\right\|>c$, then there exists a quasianalytic contraction $T$ satisfying the conditions $\sigma(T)=K^{2}:=\left\{z^{2}: z \in K\right\}$ and $\pi(T)=\mathbb{T}$ for every connected, compact set $K$, containing the upper half-circle and contained in the the closed upper half-disk.

For every $c>1$ we present a bilateral weighted shift $T_{\beta} \in \mathcal{L}_{1}(\mathcal{H})$ such that $\sigma(T)=\mathbb{T}$ and $\left\|T^{-1}\right\| \geq c$. This proves that our assumption in the previous statement holds if $J=\mathbb{T}$, moreover, relying on this statement we can provide contractions in $\mathcal{L}_{1}(\mathcal{H})$ with more sophisticated spectra. 


\section{Összefoglalás}

A disszertációban Hilbert-téren értelmezett kontrakciók aszimptotikus viselkedését és alapvetô struktúráját vizsgáljuk. Az értekezés két különbözô, abszolút folytonos (a.f.) kontrakciókkal kapcsolatos témát tartalmaz.

A 2. fejezetben kontrakciók és polinomiálisan korlátos operátorok stabilitási tulajdonságait tanulmányozzuk. A 2.1. alfejezetben karakterizáljuk a korlátos analitikus függvények azon $\left\{h_{n}\right\}_{n=1}^{\infty}$ sorozatait, melyekkel tesztelhetô az a.f. kontrakciók stabilitása, nevezetesen, melyekre $h_{n}(T)$ pontosan akkor konvergál a zéró operátorhoz az erôs operátor-topológiában, amennyiben $T$ aszimptotikusan stabil, azaz $T^{n}$ tart a zéró operátorhoz az erôs operátor-topológiában. Belátjuk, hogy pontosan a következô három tulajdonsággal rendelkezô sorozatok lesznek az előbbi értelemben vett teszt-sorozataink:

(i) $\lim _{n \rightarrow \infty} h_{n}(z)=0$ minden $z \in \mathbb{D}$ esetén,

(ii) $\sup \left\{\left\|h_{n}\right\|_{\infty}: n \in \mathbb{N}\right\}<\infty$,

(iii) $\lim \sup _{n \rightarrow \infty}\left\|\chi_{\alpha} h_{n}\right\|_{2}>0$ teljesül bármely pozitív mértékú $\alpha \subset \mathbb{T}$ Borel-halmaz esetén, ahol $\chi_{\alpha}$ az $\alpha$ halmaz karakterisztikus függvényét jelöli.

Néhány további kapcsolódó állítás igazolása után a 2.2. alfejezetben kiterjesztjük eredményeinket polinomiálisan korlátos operátorokra. Belátjuk, hogy pontosan az előbbi sorozatokkal tesztelhetô az a.f. polinomiálisan korlátos operátorok stabilitása is.

A további fejezetekben speciális aszimptotikusan nem-eltúnő kontrakciókat vizsgálunk, elsôsorban a híres invariáns- és hiperinvariáns altér problémák által motiválva. Ezekhez a kontrakciókhoz különböző unitér operátorok társíthatók, melyek tulajdonságai tükröződnek a vizsgált kontrakció viselkedésében. Az unitér aszimptota segítségével a reziduális halmazt, míg a minimális unitér dilatáció és az Sz.-NagyFoias függvénykalkulus által a kvázianalitikus spektrálhalmazt definiálhatjuk. 
A 3. fejezet elején, nevezetesen a 3.1. alfejezetben bevezetjük a lokális kvázianalitikus spektrálhalmaz fogalmát és feltárjuk a reziduális halmazzal való kapcsolatát. Kiderül, hogy az aszimptotikus sûrüségfüggvény meghatározza a lokális stabilitást, továbbá, hogy a lokális reziduális halmaz és a lokális kvázianalitikus spektrálhalmaz egybeesik tetszóleges vektor esetén. Ebból következik, hogy a (globális) kvázianalitikus spektrálhalmaz mindig része a reziduális halmaznak. Ha ez a tartalmazás valódi valamilyen $T$ kontrakció esetén, akkor $T$-nek van valódi hiperinvariáns altere. Ellenkezố esetben a $T$ kontrakciót kvázianalitikusnak nevezzük. Az értekezés legnagyobb részét ezen kontrakciók vizsgálata adja. A 3.2. részben áttekintjük a kvázianalitikus kontrakciók alapvető tulajdonságait.

Az invariáns altér probléma a kvázianalitikus esetben visszavezethető az aszimptotikusan ciklikus kvázianalitikus kontrakciók $\mathcal{L}_{0}(\mathcal{H})$ osztályára, azaz ciklikus unitér aszimptota esetére. Ezt az osztályt vizsgáljuk a 3.3. alfejezetben, ekvivalens feltételeket adunk valódi hiperinvariáns altér létezésére. A 3.15. Tétel következtében a hiperinvaráns altér probléma ebben az osztályban arra az esetre redukálható, amikor a kvázianalitikus spektrálhalmaz lefedi az egységkörvonalat, azaz az $\mathcal{L}_{1}(\mathcal{H})=\left\{T \in \mathcal{L}_{0}(\mathcal{H}): \pi(T)=\mathbb{T}\right\}$ osztályra. Ezen kontrakcióknak számos olyan invaráns alterük létezik, melyekre való megszorításuk hasonló az egyszerú egyirányú eltolás-operátorhoz. Így, amennyiben $\{T\}^{\prime}=H^{\infty}(T)$, akkor minden invariáns altér egyúttal hiperinvariáns is T-re, így ez utóbbiak is léteznek. Azonban, ha $\{T\}^{\prime} \neq H^{\infty}(T)$, akkor az eltolás típusú invariáns alterek nem hiperinvariánsak, ugyanakkor ha létezik valódi hiperinvariáns altér, akkor származtatható eltolás típusú invariáns alterekból is. Továbbá, a $\{T\}^{\prime} \neq H^{\infty}(T)$ esetben $T$ szükségképpen kváziunitér, így a hiperinvaráns altér probléma az $\mathcal{L}_{1}(\mathcal{H})$ osztályban visszavezethető a kváziunitér esetre.

Az aszimptotikusan ciklikus kvázianalitikus $T$ kontrakció $\{T\}^{\prime}$ kommutánsa azonosítható egy $\mathcal{F}(T) \subset L^{\infty}(\mathbb{T})$ függvényalgebrával, az ún. függvénykommutánssal. A 3.4. szakaszban igazoljuk, hogy ez a függvénykommutáns csak akkor pre-Douglas algebra, ha éppen a $H^{\infty}$ térrel egyezik meg, ezzel megválaszolva a [Kér01] cikkben felvetett kérdést. Bizonyítjuk $\mathcal{F}(T)$ hasonlóságra való invarianciáját is, valamint megadjuk a $\widehat{\gamma}_{T}$ függvény-leképezés reprezentációját a függvény-modellben.

A 4. fejezetet olyan speciális operátorosztályoknak szenteljük, melyekben természetes módon vetődnek fel kvázianalitikus kontrakciók. Nevezetesen, analitikus kontrakciókat és súlyozott kétirányú eltolás-operátorokat vizsgálunk.

Az [ARS07] cikkben a szerzőhármas a nyílt egységkörlapon értelmezett analiti- 
kus függvények egy általános $\mathcal{H}_{a}$ Hilbert-terén értelmezett $M_{a} \in \mathcal{L}\left(\mathcal{H}_{a}\right), M_{a} f=\chi f$ analitikus szorzás-operátort vizsgálta. A $\mathcal{H}_{a}$ tér függvényeinek határon való viselkedését meghatározza a

$$
\Delta\left(\mathcal{H}_{a}\right)=\left\{\zeta \in \mathbb{T}: \text { nt }-\underline{\lim }_{\lambda \rightarrow \zeta}\left(1-|\lambda|^{2}\right)^{-1}\left\|k_{\lambda}\right\|^{-2}>0\right\}
$$

halmaz, ahol $k_{\lambda} \in \mathcal{H}_{a}$ az az egyértelmúen meghatározott magfüggvény, melyre $f(\lambda)=\left\langle f, k_{\lambda}\right\rangle \quad\left(f \in \mathcal{H}_{a}\right)$. A 4.1. alfejezetben megmutatjuk, hogy a mérhető $\Delta\left(\mathcal{H}_{a}\right)$ halmaz mindig része $M_{a}$ kvázianalitikus spektrálhalmazának, így az [ARS07] cikkben a $\Delta\left(\mathcal{H}_{a}\right)=\omega\left(M_{a}\right)$ egyenlőségre adott feltételek teljesülése biztosítja $M_{a}$ kvázianalitikusságát. Nem nyilvánvaló, hogy egy általános analitikus szorzás-operátor unitér aszimptotája hogyan néz ki, azonban abban a speciális esetben le tudjuk írni, amikor $\mathcal{H}_{a}$ egy az [ARS09] cikkbeli feltételeket teljesítő mérték által indukált.

A 4.2. alfejezetben olyan kétirányú súlyozott eltolás-operátorokkal foglalkozunk, melyek benne vannak a $C_{10}$ osztályban. Javarészt a [Shi74] könyvben található ötleteket használjuk, azonban formális sorok helyett valódi függvényekkel dolgozunk. Az általánosság megszorítása nélkül feltehetô, hogy a vizsgált eltolás-operátoraink aszimptotikusan ciklikusak és kváziunitérek. Egy $T_{\beta}$ súlyozott kétirányú eltolásoperátorra egy bizonyos $L^{2}(\beta)$ függvénytéren értelmezett, az identikus függvénnyel való szorzás-operátorként tekintünk. Tudomásunk szerint a $C_{10}$-beli kétirányú súlyozott eltolások körében a hiperinvariáns altér probléma abban az esetben nyitott, amikor

$$
0<\delta_{\beta} \leq r_{\beta}<R_{\beta}=1 \quad \text { és } \quad \sum_{n=1}^{\infty} \frac{\log \beta(-n)}{n^{2}}=\infty .
$$

Itt a $\delta_{\beta}>0$ egyenlótlenség azt jelenti, hogy $T_{\beta}$ invertálható, $r_{\beta}$ jelöli $T_{\beta}$ belsó spektrálsugarát, a $\beta(-n)$-re vonatkozó növekedési feltétel pedig az $L^{2}(\beta)$ függvényalgebra kvázianalitikusságát biztosítja. Ezen feltételek teljesülése esetén a függvénykommutáns bizonyos körgyứrúkön értelmezett korlátos analitikus függvényekkel hozható kapcsolatba.

Habár az invariáns- és hiperinvariáns altér problémák nyitottak az aszimptotikusan nem-eltúnố kontrakciók körében, a 3.4. Következmény mutatja, hogy a nemkvázianalitikus esetben mindkét kérdés megoldott. Ezen tény ismeretében fontos lenne meghatározni a kvázianalitikus kontrakciók spektrális tulajdonságait, hiszen ha egy aszimptotikusan nem-eltûnő kontrakció nem rendelkezne ezekkel a tulajdonságokkal, akkor nem lehetne kvázianalitikus, és így létezne valódi hiperinvariáns altere. 
Amennyiben egy $T$ kontrakció kvázianalitikus, akkor a $C_{10}$ osztályba tartozik. Ezen aszimptotikus viselkedés esetén a $T$ kontrakció $\sigma(T)$ spektruma, és $V$ unitér aszimptotájának $\sigma(V)$ spektruma között kapcsolat figyelhetô meg. Nevezetesen, a $\sigma(V)$ spektrum $\omega(T)$ lényeges tartójával egyezik meg $(\sigma(V)=\operatorname{es}(\omega(T)))$, továbbá $\sigma(V) \subset \sigma(T)$ és $m\left(\sigma(V) \cap \sigma^{\prime}\right)>0$ teljesül minden olyan nem-üres zárt $\sigma^{\prime} \subset \sigma(T)$ részhalmazra, melyre $\sigma(T) \backslash \sigma^{\prime}$ is zárt. Sőt, más megszorítás nincs a $C_{10}$ kontrakciók spektrumára, még a ciklikus esetben sem; lásd az [NFBK] könyv IX. fejezetét. A záró fejezetben azt vizsgáljuk, hogy van-e további megszorítás a kvázianalitikus kontrakciók spektrumára. Négy kérdést vetünk fel és válaszolunk meg részben.

Igazoljuk, hogy, amennyiben tetszôleges $c>0$ szám és pozitív mértékú $J \subset \mathbb{T}$ zárt ív esetén létezik olyan $T$ kvázianalitikus kontrakció, melyre $\sigma(T)=\pi(T)=$ $J$ és $\left\|T^{-1}\right\|>c$ teljesül, akkor tetszóleges, a felső félkörívet tartalmazó, a zárt felső félkörben fekvô összefüggó, kompakt $K$ halmazhoz létezik olyan kvázianalitikus kontrakció, melyre $\sigma(T)=K^{2}:=\left\{z^{2}: z \in K\right\}$ és $\pi(T)=\mathbb{T}$.

Tetszôleges $c>1$ számhoz megadunk egy olyan $T_{\beta} \in \mathcal{L}_{1}(\mathcal{H})$ kétirányú súlyozott eltolás-operátort, melyre $\sigma(T)=\mathbb{T}$ és $\left\|T^{-1}\right\| \geq c$. Ezzel belátjuk, hogy az előző állításban a feltevés teljesül a $J=\mathbb{T}$ esetben, továbbá ezen példák segítségével konstruálunk további, kifinomultabb spektrummal rendelkező $\mathcal{L}_{1}(\mathcal{H})$ osztályba tartozó kontrakciókat. 


\section{Acknowledgements}

I would like to express my deep gratitude to my supervisor, Prof. László Kérchy, for his guidance, support and infinite patience.

This research was supported by the European Union and the State of Hungary, co-financed by the European Social Fund in the framework of TÁMOP 4.2.4. A/211-1-2012-0001 National Excellence Program’. 


\section{Bibliography}

[ARS07] A. Aleman, S. Richter, and C. Sundberg, Analytic contractions, nontangential limits, and the index of invariant subspaces, Trans. Amer. Math. Soc., 359 (2007), 3369-3407.

[ARS09] A. Aleman, S. Richter, and C. Sundberg, Nontangential limits in $P^{t}(\mu)$-spaces and the index of invariant subspaces, Ann. of Math. (2), 169 (2009), 449-490.

[AS54] N. Aronszajn, K. T. Smith, Invariant subspaces of completely continuous operators, Ann. of Math. (2), 60 (1954), 345-350.

[Beu77] A. Beurling, Mittag-Leffler Lectures on Complex Analysis (1977-1978), in The Collected Works of Arne Beurling, Volume 1, Birkhäuser, 361-443.

[CeP89] B. Chevreau, G. Exner, and C. Pearcy, On the structure of contraction operators. III, Michigan Math. J., 36 (1989), 29-62.

[CL66] E. F. Collingwood and A. J. Lohwater, The theory of cluster sets, Cambridge University Press, Cambridge, 1966.

[Con91] J. B. Conway, The theory of subnormal operators, Amer. Math. Soc., Rhode Island, 1991.

[CD78] M. J. Cowen and R. G. Douglas, Complex geometry and operator theory, Acta Math., 141 (1978), 187-261.

[Dou60] R. G. Douglas, On the operator equation $S^{*} X T=X$ and related topics, Acta Sci. Math. (Szeged), 30 (1960), 19-32.

[Est97] J. Esterle, Singular inner functions and biinvariant subspaces for dissymetric weighted shifts, J. Funct. Anal., 144 (1997), 64-104. 
[Foi63] C. FoiAs, A remark on the universal model for contractions of G. C. Rota, Com. Acad. R. P. Române, 13 (1963), 349-352.

[Gar07] J. B. GarnetT, Bounded analytic functions, Graduate Texts in Mathematics, Springer, New York, 2007.

[GK11] Gy. P. GEHÉr and L. KÉRCHY, On the commutant of asymptotically non-vanishing contractions, Period. Math. Hungar., 63 (2011), 191-203.

[Hal51] P. R. Halmos, Introduction to Hilbert Space and the Theory of Spectral Multiplicity, New York, 1951.

[Hof88] K. Hoffman, Banach Spaces of Analytic Functions, Dover Publications, Inc., New York, 1988.

[Kér89] L. KÉRCHY, Isometric asymptotes of power bounded operators, Indiana Univ. Math. J., 38 (1989), 173-188.

[Kér01] L. KÉRCHY, On the hyperinvariant subspace problem for asymptotically nonvanishing contractions, Operator Theory Adv. Appl., 127 (2001), 399422 .

[Kér07] L. KÉRCHY, Shift-type invariant subspaces of contractions, J. Funct. Anal., 246 (2007), 281-301.

[Kér11] L. KÉRCHY, Quasianalytic contractions and function algebras, Indiana Univ. Math. J., 60 (2011), 21-40.

[Kér13] L. KÉRChy, Unitary asymptotes and quasianalycity, Acta Sci. Math. (Szeged), 79 (2013), 253-271.

[KSz13] L. KÉRChY and A. SzAlaI, Characterization of stability of contractions, Acta Sci. Math. (Szeged), 79 (2013), 325-332.

[KSz14] L. KÉRCHY and A. Szalai, Asymptotically cyclic quasianalytic contractions, Studia Math., 223 (2014), 53-75.

[KSz15] L. KÉRChy and A. SzAlai, Spectral behaviour of quasianalytic contractions, Proc. Amer. Math. Soc., accepted.

[KT12] L. KÉRCHY and V. TOTIK, Compression of quasianalytic spectral sets of cyclic contractions, J. Funct. Anal., 263 (2012), 2754-2769. 
[Koo98] P. Koosis, A local estimate, involving the least superharmonic majorant, for entire functions of exponential type, Algebra i Analiz, 10 (3), (1998), $45-64$.

[Lom73] V. Lomonosov, On invariant subspaces of families of operators commuting with a completely continuous operator, Funkcional. Anal. i Prilozen, 7 (1973), 55-56.

[Mla73] W. MLAK, Decompositions of polynomially bounded operators, Bull. Acad. Polon. Sci. Sér. Sci. Math. Astronom. Phys., 21 (1973), 317-322.

[Mla74a] W. MLAK, Operator valued representations of function algebras, Linear Operators and Approximation. II, (Proc. Conf., Oberwolfach Math. Res. Inst., 1974), Internat. Ser. Numer. Math. 25, Birkhäuser, Basel, 1974, 49-79.

[Mla74b] W. Mlak, Algebraic polynomially bounded operators, Ann. Polon. Math., 29 (1974), 133-139.

[Nagy53] B. Sz.-Nagy, Sur les contractions de l'espace de Hilbert, Acta Sci. Math. (Szeged), 15 (1953), 87-92.

[NF74] B. Sz.-NAGY and C. FoiAs, Jordan model for contractions of class $C_{.0}$, Acta Sci. Math. (Szeged), 36 (1974), 305-322.

[NFBK] B. Sz.-Nagy, C. Foias, H. Bercovici, and L. Kérchy, Harmonic analysis of operators on Hilbert space, Revised and Enlarged Edition, Universitext, Springer, New York, 2010.

[Shi74] A. L. SHIELDS, Weighted shift operators and analytic function theory, Topics in Operator Theory (ed. C. Pearcy), Amer. Math. Soc., Providence, 1974.

[Tak90] K. TAKAhashi, On contractions without disjoint invariant subspaces, Proc. Amer. Math. Soc., 110 (1990), 935-937.

[Tol92] V. A. Tolokonnikov, Generalized Douglas algebras, St. Petersburg Math. J., 3 (1992), 455-476. 